\title{
Exploiting Nanomaterials for Optical Coherence Tomography and Photoacoustic Imaging in Nanodentistry
}

\author{
Avishek Das ${ }^{1, *(1)}$, Gisele Cruz Camboim Raposo ${ }^{2}$, Daniela Siqueira Lopes ${ }^{3}$, Evair Josino da Silva ${ }^{2}$, \\ Vanda Sanderana Macêdo Carneiro ${ }^{4}(0)$, Cláudia Cristina Brainer de Oliveira Mota ${ }^{5}{ }^{\circ}$, Marcello Magri Amaral ${ }^{6}$, \\ Denise Maria Zezell ${ }^{7}$, Renato Barbosa-Silva ${ }^{1}$ (D) and Anderson Stevens Leonidas Gomes ${ }^{1,2}$
}

\section{check for} updates

Citation: Das, A.; Raposo, G.C.C.; Lopes, D.S.; da Silva, E.J.; Carneiro, V.S.M.; Mota, C.C.B.d.O.; Amaral, M.M.; Zezell, D.M.; Barbosa-Silva, R.; Gomes, A.S.L. Exploiting Nanomaterials for Optical Coherence Tomography and Photoacoustic Imaging in Nanodentistry. Nanomaterials 2022, 12, 506. https:// doi.org/10.3390/nano12030506

Academic Editor: Pablo del Pino

Received: 29 November 2021

Accepted: 21 January 2022

Published: 1 February 2022

Publisher's Note: MDPI stays neutral with regard to jurisdictional claims in published maps and institutional affiliations.

Copyright: (c) 2022 by the authors. Licensee MDPI, Basel, Switzerland. This article is an open access article distributed under the terms and conditions of the Creative Commons Attribution (CC BY) license (https:/ / creativecommons.org/licenses/by/ $4.0 /)$.
1 Physics Department, Universidade Federal de Pernambuco, Recife 50670-901, PE, Brazil; renato.barbosa@ufpe.br (R.B.-S.); anderson.lgomes@ufpe.br (A.S.L.G.)

2 Graduate Program in Dentistry, Universidade Federal de Pernambuco, Recife 50670-901, PE, Brazil; gisele.camboim@ufpe.br (G.C.C.R.); evair.josino@ufpe.br (E.J.d.S.)

3 Faculty of Dentistry, Campus Arcoverde, Universidade de Pernambuco, Arcoverde 56503-146, PE, Brazil; daniela.siqueira@upe.br

4 Faculty of Dentistry, Campus Camaragibe, Universidade de Pernambuco, Camaragibe 54756-220, PE, Brazil; vanda.carneiro@upe.br

5 Faculty of Dentistry, Centro Universitário Tabosa de Almeida, Caruaru 55016-901, PE, Brazil; claudiamota@asces.edu.br

6 Scientific and Technological Institute, Universidade Brasil, Fernandópolis 15600-000, SP, Brazil; marcello.magri@universidadebrasil.edu.br

7 Center for Lasers and Applications, Instituto de Pesquisas Energéticas e Nucleares IPEN-CNEN, São Paulo 05411-000, SP, Brazil; zezell@usp.br

* Correspondence: avishek55das@gmail.com

\begin{abstract}
There is already a societal awareness of the growing impact of nanoscience and nanotechnology, with nanomaterials (with at least one dimension less than $100 \mathrm{~nm}$ ) now incorporated in items as diverse as mobile phones, clothes or dentifrices. In the healthcare area, nanoparticles of biocompatible materials have already been used for cancer treatment or bioimaging enhancement. Nanotechnology in dentistry, or nanodentistry, has already found some developments in dental nanomaterials for caries management, restorative dentistry and orthodontic adhesives. In this review, we present state-of-the-art scientific development in nanodentistry with an emphasis on two imaging techniques exploiting nanomaterials: optical coherence tomography (OCT) and photoacoustic imaging (PAI). Examples will be given using OCT with nanomaterials to enhance the acquired imaging, acting as optical clearing agents for OCT. A novel application of gold nanoparticles and nanorods for imaging enhancement of incipient occlusal caries using OCT will be described. Additionally, we will highlight how the OCT technique can be properly managed to provide imaging with spatial resolution down to $10^{\prime} \mathrm{s}-100^{\prime}$ s nm resolution. For PAI, we will describe how new nanoparticles, namely TiN, prepared by femtosecond laser ablation, can be used in nanodentistry and will show photoacoustic microscopy and tomography images for such exogenous agents.
\end{abstract}

Keywords: nanomaterial; nanodentistry; optical coherence tomography; photoacoustic imaging

\section{Introduction}

Nanoscience and nanotechnology, which deals with science and technology at the nanoscale, have developed in such a way that it has already been used in several areas of knowledge, with social applications and economic impact [1]. From the Internet of Nano Things [2] to health benefits [3], exploiting the nanoworld has made a big impact. This is no different in dentistry, although still in its infancy with respect to other areas of healthcare [4]. The authors of ref. [5] provided a good and updated account of nanomaterials in a diversity of dentistry applications. Among those, dental materials have received increasing attention [6], dental nanomaterials for caries management [7], restorative dentistry [8] and 
orthodontic adhesives [9]. Additionally, another importance to nanodentistry is silver nanoparticles, due to their antibactericidal properties [10]. Nanomaterials can be prepared, grown or synthesized using bottom-up or top town techniques, and refs. [5,11] brings an updated review highlighting recent developments regarding therapeutic applications of nanomaterials in dentistry, including chemistry, synthesis, properties and benefits of therapeutic nanomaterials over conventional materials.

From the point of view of imaging techniques, nanomaterials of different materials and shapes have already played an important role, as reviewed in [12]. Within the scope of this review, we will describe how nanomaterials have been exploited with optical coherence tomography (OCT) and photoacoustic imaging (PAI), in two modalities: photoacoustic microscopy (PAM) and photoacoustic tomography (PAT). We anticipate that both OCT and PAI are well-known and established imaging methods, as will be described in more detail in Section 3. As a common feature to both, a light source is used to illuminate (or excite) the sample, whereas the detection in the OCT is also in the optical regime, and the PAI detection is in the acoustic regime. Two important features are penetration depth and spatial resolution. For OCT, the penetration depth is limited by the absorption and scattering to a few millimeters, whereas for PAI it can achieve a centimeter range, thanks to acoustic wave propagation. Furthermore, spatial resolution, which means how small can one resolve the spatial features in the sample, can be measured in submicrometers in both methods. For OCT, this spatial resolution is determined in the axial direction by the optical source bandwidth, and the lateral resolution by the optics employed. In PAI, this is given by a combination of the incident optical geometry and acoustic detector bandwidth. Therefore, to overcome some of these issues, a combination of OCT+PAI operating in a multimodal fashion has been reported, which overcomes the penetration depth-resolution duality. Noticeable is that because the PAI detection is in the acoustic regime, a single detector can be used at any optically excited range, and this is a great advantage. This paper highlights to the readers the combination of the two imaging techniques, their application in nanodentistry which is related to the dental application in the nanoscale regime, and is organized as follows: In Section 2, we briefly give a background account on the field of nanodentistry, highlighting nanofabrication methods. In Section 3 and its subsections, we start with a general view on imaging techniques, and then describe imaging by OCT, from the basics to applications in nanodentistry. Further, we describe imaging by photoacoustics, with basic insights and imaging by PAM and PAT with TiN nanoparticles. In Section 4, we draw some conclusions and provide an outlook.

As a disclaimer, we point out that this is not a broad and deep literature review, but rather a review of some aspects of two imaging techniques (OCT and PAI) applied to nanodentistry, with literature and our own laboratory results.

\section{Nanodentistry}

Nanodentistry deals mainly with nanobiomaterials applied to dentistry and is a growing field of research with high potential for clinical translation [4,5,13-19]. It is a term also employed when characterization techniques in the nanoscale regime are employed for dental materials and tissues. The so-called dental nanobiomaterials are fabricated by well-developed nanofabrication processes (see more details in ref. [15]). Naturally occurring nanostructures, particularly nanobiostructures present in biotissues, are subject to intense attention from researchers worldwide, not only for imaging but also for seeing those nanostructures in situ and working is out of the scope of this article.

Nanofabrication processes are generally classified by two approaches: the top-down and the bottom-up. As the terms indicate, the former means that, by starting from bulk materials, nanosized structures are formed. Conversely, starting with atoms or molecules, nanostructures can be formed. Figure 1 shows examples of top-down and bottom-up routes, indicating some of the techniques that have been used to achieve nanostructures. From an economic point of view, the bottom-up approach is cheaper than the top-down. 


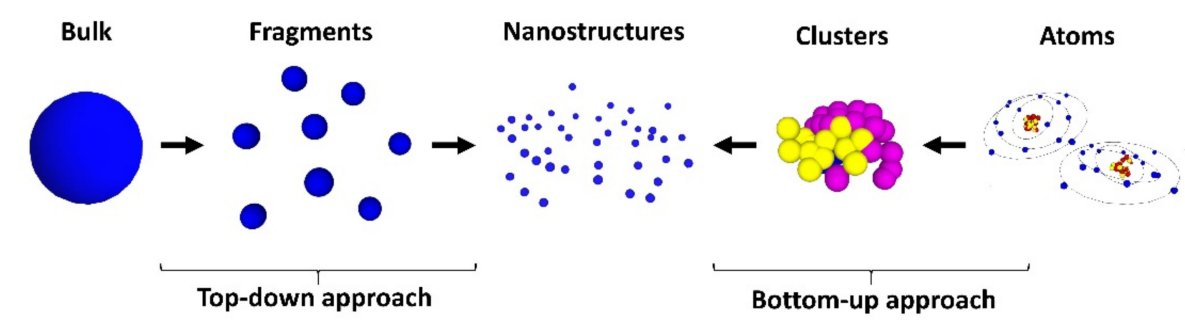

Figure 1. Top-down and bottom-up approaches used in nanofabrication.

As a result of the growth and development of the nanofabrication processes, it is possible nowadays to have access to organic or inorganic nanostructures, which can be dielectric, such as $\mathrm{TiO}_{2}$ or rare-earth-doped materials, semiconducting, as $\mathrm{ZnO}$, or metallic nanoparticles, as Au or Ag, and of different structures and shapes, such as nanoparticles, nanoshells or nanorods, dimensions, and so on. These make the physical properties of these nanomaterials very morphology dependent.

Figure 2 shows examples of organic and inorganic nanomaterials, with typical shapes widely exploited in nanoscience and nanotechnology.

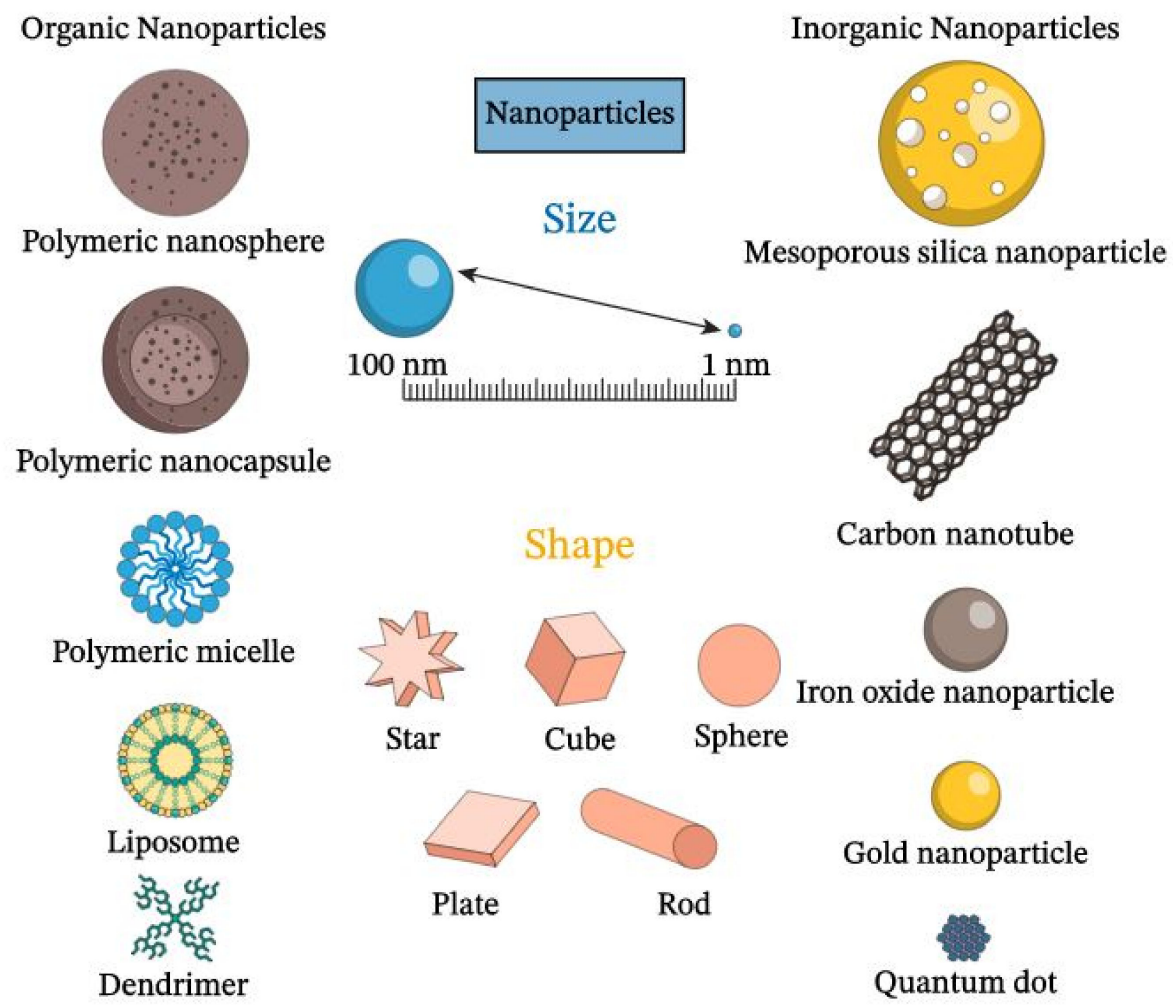

Figure 2. Types and shapes of nanoparticles. (Downloaded from https://www.nagwa.com/en/ explainers /640142370207/, accessed on 7 November 2021).

\section{OCT and PAI Imaging Techniques}

Diagnostics by medical imaging is one of the most prominent diagnosing techniques for pathologies due to some of their unique advantages: noninvasiveness, the amplitude of penetration depth and spatial resolution (depending upon the technique employed), real-time assessment and, nowadays, using artificial intelligence methods [20]. Besides exploiting the internet-of-things associated with 5G or the arriving 6G, this technology promotes online access for specialists anytime, anywhere [21]. Among the myriad of methods, this review focuses on two complementary and already well-known bioimaging techniques: 
optical coherence tomography (OCT) [22] and photoacoustic imaging (PAI) [23], focusing on nanodentistry. As already mentioned, in common, these two methods use optical excitation sources, and differ in the detection method, with OCT keeping an all-optical setup, whereas PAI uses acoustic detection. In Figure 3, a comparison of three key factors-spatial resolution, penetration depth, and imaging speed-which are characteristics of imaging techniques, were compiled by Zhu and co-workers in the context of neuroimaging [24] but applies well to other medical imaging applications. In the X-axis, the penetration depth for each technique indicated is shown, which for OCT depends upon the absorption and scattering coefficients (which, when combined, gives the tissue extinction coefficient). Note the typical 1-3 $\mathrm{mm}$ penetration depth for OCT, and $1 \mathrm{~mm}$ to several $\mathrm{cms}$ for PAI, with an overlap region in the $\mathrm{mm}$ spatial regime. The Y-axis gives the spatial resolution (see Section 3.1), mainly given by the axial resolution. For OCT, it is the inverse of the source bandwidth which determines the axial resolution, such as those arising femtosecond laser sources or superluminescent diodes, or even from a swept-source with a narrow line laser. For OCT, as seen in the Y-axis of the figure, sub-micron spatial resolution can be achieved. The transverse resolution (see Section 3.1) is given by the optics employed-normally microscope objectives. On the other hand, the spatial (axial) resolution for PAI is lower than for OCT, although nowadays it can also go into the submicrometer regime (see Section 3.4 for details and references). The image speed on the right-hand side includes the computational process. For OCT, its order of magnitude varies if one considers an A, B or C-scan. For PAI, the overall image procedure is displayed on the screen for analysis. This illustrative Figure 3 shows (a) how fast OCT response is compared to PAI; (b) the penetration depth for both methods; and (c) the higher spatial resolution of OCT compared to PAI, at the expense of penetration depth. By combining both techniques for a given sample and region of interest, it may be very feasible to extend the spatial resolution range by about a factor of 1000 and penetration depth by a factor of 100 . All the above features are valid for biological tissues, but can also be employed for nonbiological tissues, as long as there is absorption in the region of interest of the sample.

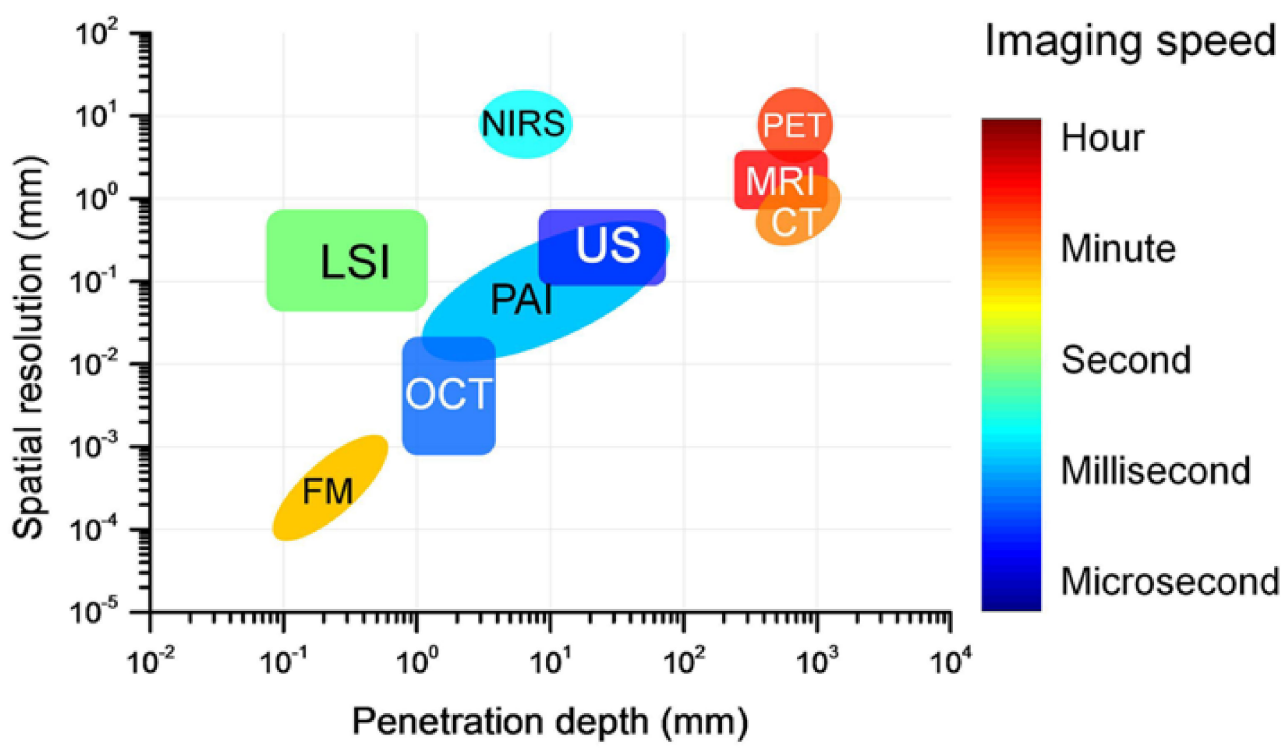

Figure 3. Comparisons of the penetration depth, spatial resolution and image speed among various techniques for neuroimaging, including magnetic resonance imaging (MRI), computed tomography (CT), positron emission tomography (PET), ultrasound imaging (US), optical coherence tomography (OCT), photoacoustic imaging (PAI), fluorescence microscopy (FM), near-infrared spectral imaging (NIRS), and laser speckle imaging (LSI). Reprinted with permission from ref. [24]. 


\subsection{OCT: From Basics to Applications in Nanodentistry}

OCT exploits the broad spectral width of a low coherence optical source, in combination with a Michelson-type interferometer, to retrieve high resolution (submicrometer) images with low penetration depth (few $\mathrm{mm}$ ), relying on the interference between the backscattered light from tissue and the reflected beam from the reference arm. The OCT technique was pioneered in 1991 when Huang and co-workers first described a tomographic image of the eye retina [25]. Since then, scientific and technological developments in the OCT technique evolved exponentially, and the reader is referred to the authoritative book by Fujimoto and Drexler [26]. Instead of giving an extensive list of references in OCT and its diversity of applications in medical and non-medical areas, the reader is also referred to the public webpage www.octnews.org, a trusted and always updated webpage for OCT developments.

Conceptually, OCT is a very simple method (see Figure 4A): a spectrally broadband optical beam, which can be generated by coherent or incoherent sources and travels through a Michelson-interferometer, with the beam being split to the reference arm and the other arm which has the sample under study. When ultrashort Fourier transformed limited pulses are employed, they are not chirped. Otherwise, the optical sources employed are chirped. The reflected light from the surface and inner parts (including scattered light) of the biological samples thus interferes with the light returned from the reference arm, providing an interference pattern that carries the image information. The spatial resolution, Figure 4B, is provided in two directions: the axial resolution of the system is determined by the optical source and is inversely proportional to its bandwidth. The lateral resolution depends on the employed focusing optics, either lenses or microscope objectives. A very important point is the role of absorption and scattering. For this reason, an OCT system performs better in the $800 \mathrm{~nm}-1300 \mathrm{~nm}$ spectral window, also known as the NIR-I or NIR-II window [27]. Below $800 \mathrm{~nm}$ (towards the visible) absorption may hinder light penetration, and therefore working in the NIR-I and NIR-II allows deeper penetration. Furthermore, tissue scattering is also reduced as the light wavelength increases from the visible to the NIR, which is another advantage. The pioneer OCT systems operated in the so-called temporal or time-domain OCT (TD-OCT), but the technological development led to the exploitation of Fourier-domain methods, which can be spectral-domain OCT (SD-OCT) and swept-source OCT (SS-OCT). Figure 4, adapted from ref. [22], depicts the different experimental schemes for those systems, indicating the detection systems (photodetector or CCD array), axial and lateral image resolution and depth of field (which depends upon source bandwidth and optics). In the SD-OCT, because the spectrum of the beam after interference is obtained by the spectrometer, rather than by a single detector as in the SS-OCT, the nomenclature is slightly different in Figure $4 \mathrm{~A}$, although both are optical detectors.

(A) Time-Domain OCT

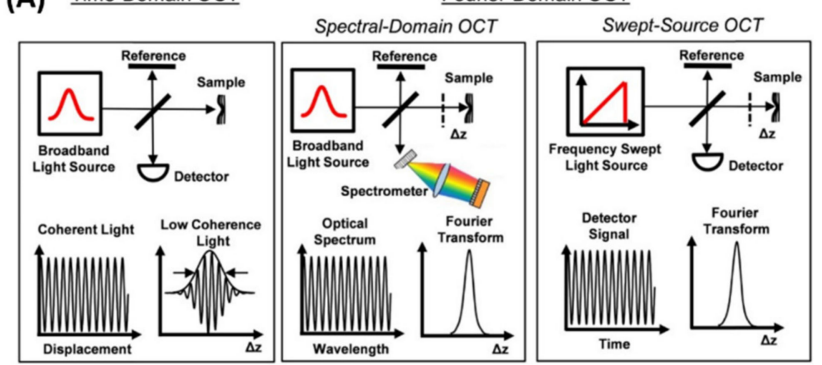

(B)

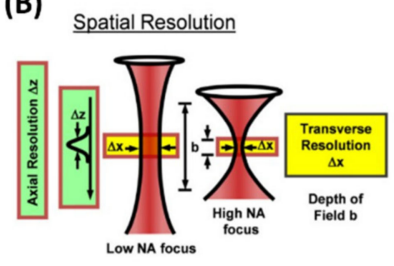

Figure 4. (A) Key concepts of OCT, including TD-OCT, SD-OCT, and SS-OCT detection; (B) Axial and lateral image resolution and depth of field; Adapted with permission from ref. [22]. 
The results obtained by OCT can be displayed by the so-called A-scan, whereby a single depth profile is shown (without lateral displacement of the beam); B-scan, whereby the beam is laterally displaced and the collected data is composed of a set of $2 \mathrm{D}$ frames and finally, the C-scan, which provides a 3D image by acquiring a volume dataset of B-scans. Figure 5 shows diagrammatically each scheme, applied to OCT in the eye as an example. For further details and alternative schemes for OCT, the reader should consult ref. [26].

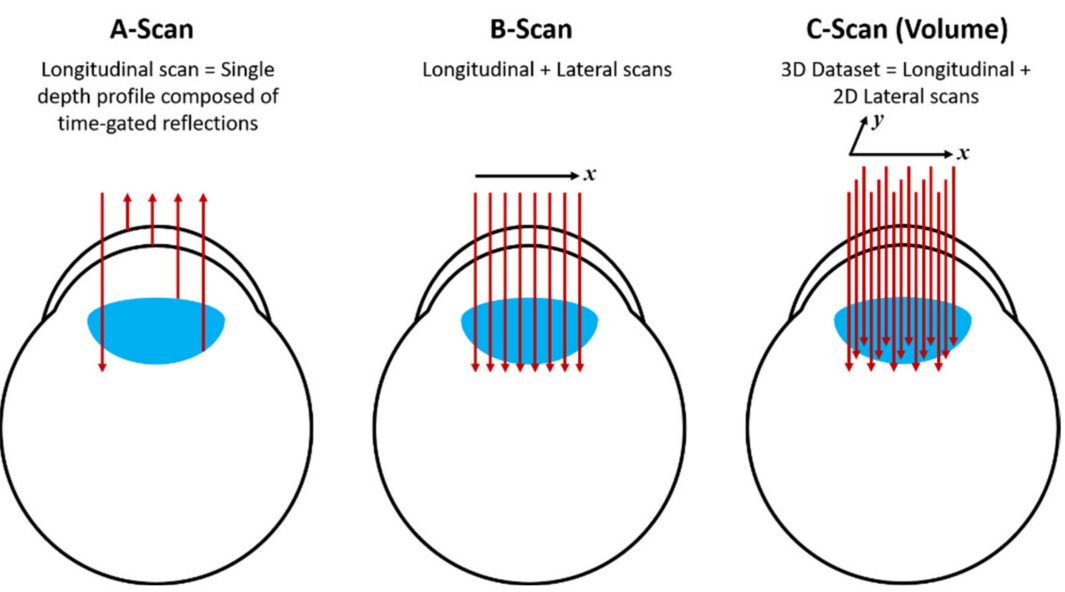

Figure 5. Diagram showing the A-scan, B-scan and C-scan obtained from the OCT method.

\subsection{OCT in Nanodentistry: Image Enhancement with Gold Nanoparticles}

The applications of OCT in dentistry have been reviewed on a number of occasions [28-30]. Our group in Brazil has employed OCT for dental applications in the areas of cariology, endodontics, periodontology, aesthetics and dental materials, as exemplified by refs. [31-41]. OCT in nanodentistry can be seen from two perspectives: (a) the OCT technique operates such as to improve the sensitivity or detect in the nanometer regime or (b) the OCT technique can be employed to study nanostructures in dental materials or dental tissues (hard or soft).

From the first perspective, we call the reader's attention to the work of Martin Leahy's group [42-44] and the work of J. Yi and co-workers [45]. In [42-44], a technique called nanosensitive OCT (nsOCT) was developed and demonstrated, which exploits proper manipulation of the micrometer resolution data from Fourier-domain OCT to resolve the images in the nanoscale $\left(10^{\prime} \mathrm{s} \mathrm{nm}\right)$ regime and was recently applied to assess wound healing within the cornea [44]. Further, J. Yi and co-workers developed a so-called inverse spectroscopic OCT (ISOCT), which, upon quantification of the wavelength-dependent backscattering coefficient $\mu_{\mathrm{b}}(\lambda)$ and the scattering coefficient $\mu_{\mathrm{s}}$ ), quantify the mass-density correlation function to achieve detectable structural changes ranging from $\sim 30$ to $\sim 450 \mathrm{~nm}$. The authors validated their findings by numerical simulations, tissue phantom studies, and ex-vivo colon tissue measurements, which were cross-validated by scanning electron microscopy. For further details of both methods, the readers should assess the given references.

From the second perspective, OCT can be employed to assess nanostructures within the sample. We give some examples from our own group, whereby a commercially available OCT system was employed. In reference [46], within an international collaborative work, a pioneer application of OCT in nanodentistry was reported, whereby gold nanoparticles $(\mathrm{AuNP})$ were formed in situ and immediately used as a contrast agent for dental OCT. This development was essential to imaging the desired region. Figure 6a shows an artistic view of a tooth structure, highlighting the dentinal tubules. 
a
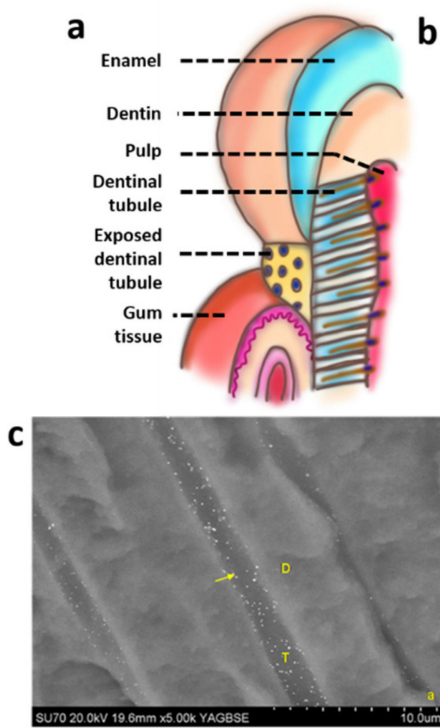

b
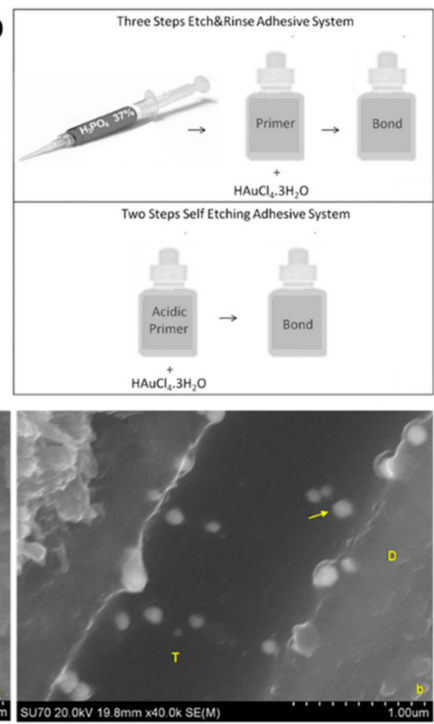

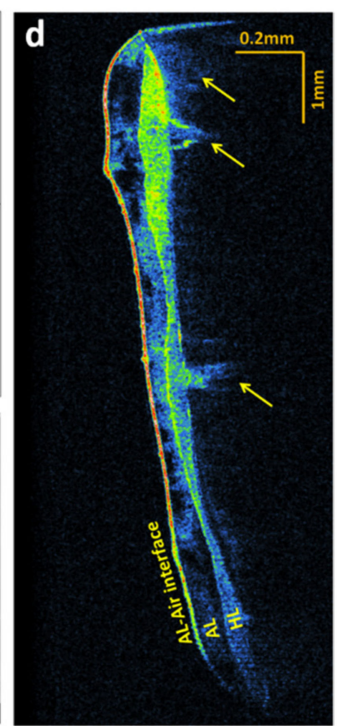

Figure 6. (a) Artistic rendering of dentinal tubules and its connection to the pulp; (b) Steps for the in situ gold nanoparticle preparation; (c) SEM images of dentinal tubules, showing the gold NP; (d) OCT image of the dentinal tubules, only possible due to the presence of gold NPs. Figures (b-d) reprinted with permission from [46].

To perform the work, an innovative in situ photothermal reduction procedure was developed and implemented, which allowed the production of spherical AuNP inside dentinal layers and tubules. A three-step procedure was performed: First, gold ions were dispersed in the primer of a commercially available dental bonding system. Secondly, the modified adhesive system was applied to the dentin, and the dental bonding materials were photopolymerized using a commercially available photopolymerizer, simultaneously with the formation of AuNP, as shown in Figure 6b. The presence of AuNP was confirmed by scanning electron microscopy in the hybrid layer and dentinal tubules, as seen in Figure 6c. The diameter of the AuNP was determined to be in the range of 40 to $120 \mathrm{~nm}$, while it is known that the dentin tubule's diameters ranged from 500-4000 nm. Figure $6 \mathrm{~d}$ shows the OCT images of the samples with and without AuNP. The ultra-intense regions of OCT images show highly scattering portions and high levels of direct light backscatter, due to the presence of AuNP within the imaged volume. This information is displayed in false colors in Figure 6d: warm colors for higher and cool colors for lower scattering intensities, respectively. Without AuNP, the image is not shown since it cannot be resolved. In comparison, as indicated by the arrows in Figure 6d, the tubules become detectable and easily visible with the presence of the AuNP, acting as contrast agents to enhance the OCT image. Further details can be appreciated in ref. [46].

\subsection{OCT in Nanodentistry: Association of AuNP and AuNR as Contrast Agents for Imaging Enhancement}

As another nanodentistry application, our group has exploited silver and gold nanostructures as optical clearing agents (OCA), or contrast agents, as enhancers to improve caries diagnostic by optical coherence tomography. Silver nanoparticles are well-known as biocompatible and antibactericidal agents, already employed in nanodentistry [47-50]. Nonetheless, the role of optical clearing agents in biotissue imaging is a very active subject, which found its way after Tuchin and co-workers [51], as recently reviewed in ref. [52]. A handbook on the subject covers a highly updated account of this field [53]. The final action of optical clearing agents is to provide deeper penetration depth for imaging and other healthcare purposes. As pointed out in [47-52], the physical process of optical clearing consists of the immersion/permeabilization of biocompatible chemical substances in bio- 
logical tissues. Due to a series of effects of these substances on the biosample, such as the compatibility of refractive indices, cell dehydration and the increase of collagen solubility arising from osmotic properties of the OCA, the optical clearing effect occurs. OCA using biocompatible chemical substances have been used in skin, bone, cartilage, luminal organs and other connective tissues (see [52,53] and refs therein). There is a vast literature on OCAs associated with OCT applied to the skin [54], molecular diffusion in tissue [55], the role of glucose concentration [56] and articular cartilage in subchondral bone [57]. With similar aiming of enhancing imaging in OCT systems, nanomaterials-particularly gold nanoparticles, nanoprisms and nanorods, besides $\mathrm{TiO}_{2}$ nanoparticles-have been exploited as contrast agents in cardiovascular OCT imaging [58], angiography [59], breast carcinoma [60], as well as phantoms [61]. OCA also plays an important role in dentistry. When analyzing a tooth surface with the OCT device, the presence of caries lesions typically promotes a large increase in light scattering due to demineralization, therefore limiting the light penetration, and reducing the OCT signal before it even reaches the dentinenamel junction [62]. In this way, OCA may provide deeper penetration and improve OCT image quality in situ, whereas an agent that modifies the diffusion properties of a sample may improve the image contrast. The use of nanoparticles as contrast agents in dentistry was already mentioned in this review [46]. More recently, silver nanoparticles $(\mathrm{AgNP})$ in aqueous solution and diluted in glycerol have been exploited as OCA for a diagnostic of occlusal incipient caries lesions through OCT imaging, based on the changes in enamel birefringence and highlighting demineralized areas [47]. As a conclusion of ref. [47], OCA with AgNP evidenced the enamel birefringence and demarcated initial demineralization areas, presenting images with defined margins, a higher contrast between sound and demineralized regions, with higher OCT signal intensity in such areas. As a follow up of that work, and in order to give some more technical details, we added to this review further results using gold nanoparticles and nanorods, a biocompatible noble metal, as OCA in dentistry, whose complete account can be found elsewhere (Gisele C Cruz, MSc Thesis, "Use of gold nanostructures as optical compensation agents for incipient caries analysis with optical coherence tomography" available in Portuguese at https:/ / repositorio.ufpe.br/handle/123456789/33796, accessed on 9 January 2022).

The experiments were carried out with ten extracted permanent molars with incipient caries lesions that were obtained from a teeth bank (Centro Universitário Tabosa de Almeida (ASCES-UNITA), Caruaru, Pernambuco, Brazil) which, after being divided into groups, were investigated for contrast enhancement by the alterations of the light extinction coefficient with OCT. Group (G1) was the control, whereas other groups were observed using the following components: glycerol (G2), AuNP (G3), AuNP diluted on glycerol (G4), AuNR (G5), and AuNR diluted on glycerol (G6). It is important to note that occlusal caries lesions are routinely detected using visual, tactile and exploratory methods in combination with radiographic exams [63], which have low sensitivity for occlusal lesions. The spherical gold nanoparticles (AuNP) were produced in the Department of Physics and Chemistry in the Universidade Federal de Pernambuco, Brazil by treating hydrogen tetrachloroaurate $\left(\mathrm{HAuCl}_{4}\right)$ with polyvinylpyrrolidone (PVP-MW $\left.\cong 55,000\right)$ in boiling water, where the PVP acts as a stabilizing agent. The resulting colloidal gold nanoparticles are spherical and have $2.0 \pm 1.0 \mathrm{~nm}$ dispersed in an aqueous solution, and were characterized by the peak plasmon resonance at $550 \mathrm{~nm}$ [64]. The nanorods (AuNR), however, were purchased from NanopartzTM (Nanopartz Inc., Denver, CO, USA), with $50 \mathrm{~nm}$ diameters and $160 \mathrm{~nm}$ length, and were also dispersed in aqueous solution, with two plasmon resonance peaks at $520 \mathrm{~nm}$ and $825 \mathrm{~nm}$, corresponding to the transverse and longitudinal plasmon resonances, respectively.

The studied teeth contained white or brownish spots accompanying anatomical accidents of the occlusal surfaces, but they did not have evident cavitation when analyzed by visual examination in accordance with the ICDAS code (1) first visual change in dry enamel and (2) distinct visual change in moist enamel. Teeth were excluded when caries cavities were observed by visual examination or restorations. The teeth selected for this study had 
their root portions included in a colorless chemically activated acrylic resin matrix with the occlusal surface parallel to the ground. Afterwards, they were placed on a PVC platform so they could be repositioned to receive the OCAs for OCT scanning. Each sample was analyzed a total of six times. The first one was the negative control (G1), which did not undergo any treatment, and then they were analyzed with five different combinations of optical clearing agents (OCA) and contrast agents (CA). Pure glycerol was a positive control (G2). The other OCA/CA combinations were: (G3) gold spherical nanoparticles (AuNP) dispersed in water; (G4) AuNP dispersed in water and diluted to $50 \%$ by weight of glycerol; (G5) nanorods (AuNR) dispersed in water; (G6) AuNR dispersed in water and diluted to $50 \%$ by weight of glycerol. After applying the OCA/CA, the specimens were scanned by OCT, and then the samples were washed with neutral detergent (Ypê, Amparo, São Paulo, Brazil) with Robinson's brush, followed by an ultrasonic bath in deionized water for 15 min between each OCA/CA application. In this way, all samples could be scanned by OCT in the presence of each OCA/CA combination.

The OCT system employed was a commercially available model (Callisto, Thorlabs Inc., Newton, NJ, USA), operating in the spectral-domain (SD-OCT), with $930 \mathrm{~nm}$ of central wavelength, $100 \mathrm{~nm}$ of bandwidth, a maximum output power of $5 \mathrm{~mW}$, resolution of $5.3 / 7 \mu \mathrm{m}$ in air and water, respectively, and a lateral resolution of $8 \mu \mathrm{m}$ and depth of light penetration of $1.7 \mathrm{~mm}$. The analysis was performed along the occlusal surface, capturing two-dimensional images with an $8 \mathrm{~mm}$ transverse scan of the specimens. To standardize the scanning, the samples were positioned on a two-axis linear translation stage with a rotating platform and solid top plate, and images were acquired every $250 \mu \mathrm{m}$ along the mesiodistal dimension. The two-dimensional images constitute a numerical matrix of 2000 columns at the $\mathrm{X}$-axis, corresponding to maximum $8 \mathrm{~mm}$ scanning, and 512 rows at the Y-axis, with $1.7 \mathrm{~mm}$ maximum depth (in air, refractive index 1 ). The acquired OCT images were analyzed using in-house developed software to measure the optical attenuation coefficient $(\mu)$. The $\mu$ coefficient is a quantitative value that characterizes the decay of OCT signals when light propagates through the tissue analyzed. Thus, by measuring the $\mu$ it is possible to use the OCT signal to quantitatively discriminate between different types of tissues and their state of health $[62,65]$. For the $\mu$ coefficient analysis, the software operator uploaded the images of each studied group. In each image, the operator selected the width and position of two windows with the region of interest (ROI). For standardization, the window width was maintained constant (10 A-scan) during all the analyzes. As each biological sample presents distinct morphological characteristics, the position of the windows was adjusted for each image, always positioning one window in a region of healthy tissue and the other one in a region of abnormal tissue.

Using the B-scan mode, the software identifies the surface of the tissue (air-tissue interface) and uses it as a reference to perform an average of the normalized A-scan inside each ROI window. The A-scan was normalized by the maximum value to avoid erroneous values due to possible reflection on the first surface. The average A-scan of each ROI window was used to fit an exponential decay, based on the Beer-Lambert law, $\mathrm{I}(\mathrm{Z})=\mathrm{I}_{0} \exp$ $(-\mu z)$, where $I(Z)$ is the intensity as a function of depth, $z$ and $\mu$ is the optical attenuation coefficient. The obtained $\mu$ value was recorded for posterior analysis. This procedure was repeated for each image. Statistical analysis was performed using GraphPad Prism 7 software (GraphPad Software, Inc., San Diego, CA, USA). A mean and standard deviation of each group were calculated. Normal distribution was not performed by the KolmogorovSmirnov test. To analyze differences between the groups, the Kruskal-Wallis test was used. In all groups, Student's $t$-test was performed. To verify if there was a difference between groups, the "repeated measures of variance RM-ANOVA" test was used. The statistical significance of all tests should be considered as $p<0.05$.

In order to quantify the OCT signal intensity in the dentin-enamel junction (DEJ) area, the $\mu$ coefficient of each group was obtained in sound and affected areas (Table 1). Figure 7 shows the B-scan (2D pictures) and the A-scan graphics (on the right-hand side) of the window corresponding to the pit area in G1 (control), G3 (AuNP), and G6 (AuNR + 
glycerol). Both G3 and G6 evidenced the greatest difference in the attenuation coefficient compared with the control group. The images were obtained with a horizontal sweep of $6 \mathrm{~mm}$, and the bar scale is the same for all pictures. The central yellow line shows where the A-scan was measured.
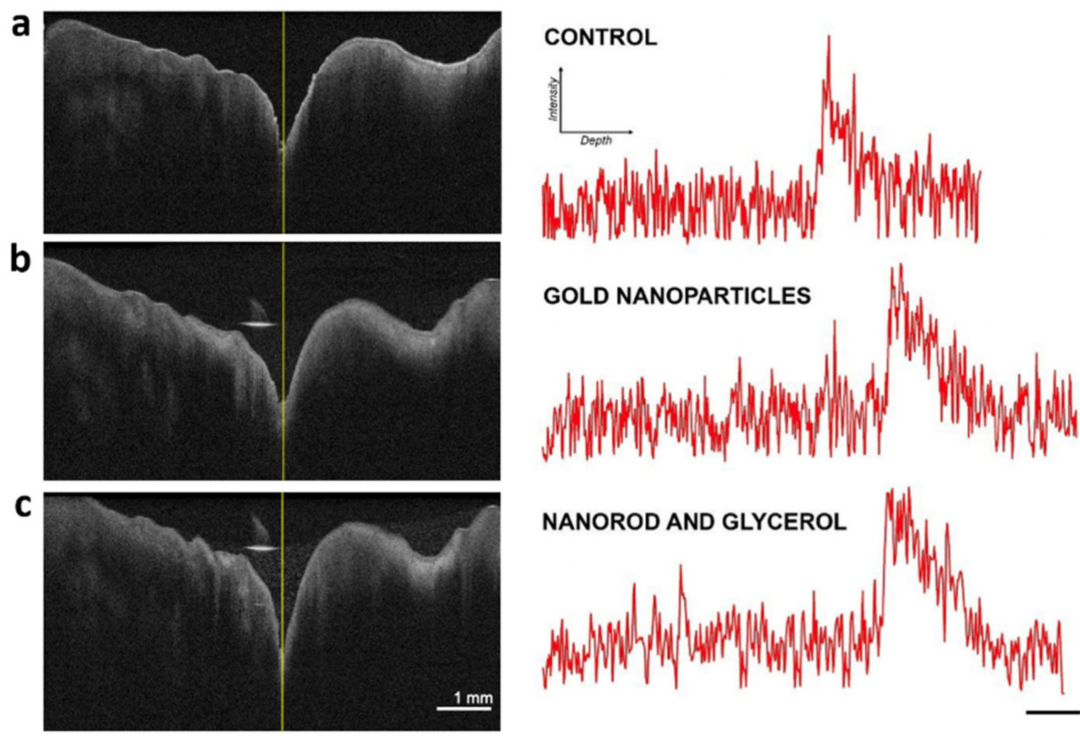

Figure 7. OCT B-scan images across occlusal surface of a molar, followed at right by the corresponding light intensity decay obtained from an A-scan of the region of interest (ROI) in the central pit area, according to OCAs used on the surface: (a) G1-Control; (b) G3-AuNPs; and (c) G6-AuNRs in glycerol.

Table 1. Mean \pm S.D. of the $\mu$ coefficient $\left(\mathrm{mm}^{-1}\right)$ values, taken from OCT images of sound and carious areas of teeth analyzed with optical clearing agents and contrast agents (OCA/CA). The RM-ANOVA analysis indicates that the values are not statistically different in the groups for sound and caries surfaces $(p>0.05)$

\begin{tabular}{|c|c|c|c|c|c|c|c|}
\hline Surface & Group (G) & $\mathbf{N}$ & $\begin{array}{c}\text { Mean } \\
\left(\mathrm{mm}^{-1}\right)\end{array}$ & SD & Minimum & Maximum & $p$-Value ${ }^{1}$ \\
\hline \multirow{6}{*}{ Sound area } & Control (G1) & 10 & 0.161 & 0.04 & 0.093 & 0,251 & $<0.0001$ \\
\hline & Glycerol (G2) & 10 & 0.169 & 0.06 & 0.087 & 0.257 & $<0.0001$ \\
\hline & Gold Nanoparticles (G3) & 10 & 0.133 & 0.06 & 0.036 & 0.25 & 0.0001 \\
\hline & $\begin{array}{l}\text { Gold Nanoparticles and } \\
\text { Glycerol (G4) }\end{array}$ & 10 & 0.143 & 0.05 & 0.063 & 0.242 & $<0.0001$ \\
\hline & Nanorod (G5) & 10 & 0.135 & 0.07 & 0.007 & 0.233 & 0.0002 \\
\hline & Nanorod and glycerol (G6) & 10 & 0.168 & 0.04 & 0.086 & 0.248 & $<0.0001$ \\
\hline \multirow{6}{*}{ Carious area } & Control (G1) & 10 & 0.184 & 0.05 & 0.136 & 0.292 & $<0.0001$ \\
\hline & Glycerol (G2) & 10 & 0.198 & 0.07 & 0.069 & 0.307 & $<0.0001$ \\
\hline & Gold Nanoparticles (G3) & 10 & 0.224 & 0.03 & 0.145 & 0.276 & $<0.0001$ \\
\hline & $\begin{array}{c}\text { Gold Nanoparticles and } \\
\text { Glycerol (G4) }\end{array}$ & 10 & 0.191 & 0.03 & 0.116 & 0.259 & $<0.0001$ \\
\hline & Nanorod (G5) & 10 & 0.214 & 0.04 & 0.158 & 0.269 & $<0.0001$ \\
\hline & Nanorod and glycerol (G6) & 10 & 0.224 & 0.05 & 0.109 & 0.291 & $<0.0001$ \\
\hline
\end{tabular}

\footnotetext{
${ }^{1}$ One sample $t$-test.
} 
An inspection of Table 1 shows an increase in the light attenuation in all carious tested groups when compared with G1 (0.184). It can be observed that groups three and six obtained a higher $\mu(0.224)$ on the carious surface. However, at the sound areas, gold nanorods diluted in glycerol $(\mathrm{G} 6=0.168)$ showed an attenuation coefficient similar to that obtained from the isolated samples in the presence of glycerol isolated G2 (0.169).

As already discussed in this review, OCAs may enhance the OCT depth penetration, whereas a contrast agent that modifies the diffusion properties of a sample may improve the image contrast. The results of this section, exploiting gold nanoparticles and gold nanorods, confirmed that the use of contrast agents increased the optical attenuation coefficient of subsurface lesions located under enamel on the occlusal surface. Furthermore, the difference between the optical attenuation coefficients of sound teeth and carious lesions increased, making the gold NP and NR a potential tool to improve the identification of lesions. Glycerol is one of the most used and tested OCAs, both in soft and hard tissue, as already indicated by several references. It has a high viscosity, 1.42 pa at room temperature, and refractive index $n=1.47$. This is well suited for use in dental imaging due to its biocompatibility, constituting an important advantage for OCT imaging, and therefore justifying the use of glycerol in some groups (G2, G4 and G6) of the present study. Within the spectral range of interest in this study, the attenuation coefficient remained similar in all groups which had a glycerol addition, even with gold nanoparticles.

In order to improve the NP OCAs properties, such as viscosity, the dispersion of the NP in glycerol was tested (to compare with them in water, the vehicle used to NPs which is less viscous than glycerol). However, the results, in this case, did not show a statistically significant difference. Finally, we note that, in contrast with the literature, the glycerol increased the optical attenuation coefficient, which means that the light penetrated less than in the control group, and thus opposed literature findings, as this agent promoted an increase in light penetration $[55,66]$. One possible explanation is that in the mentioned refs. [55,66], the OCA is used in soft tissues, not hard tissue as here; however, this claim needs to be further verified.

\subsection{PAI: From Basics to Nanodentistry Applications}

As pointed out in the introduction of this section, PAI relies on the acoustic response of a biotissue upon excitation with light, which is absorbed by the medium. The absorbed photons lead to local heating, followed by the expansion/contraction and generation of acoustic waves. PAI can be understood as a hybrid modality that relies on the interplay between absorption of light with subsequent ultrasound emission. It is a well-known imaging modality $[23,67,68]$ and well-developed technologically.

Figure 8 shows the basic principles of the photoacoustic effect [69]. A pulsed optical source, generally a laser due to its high intensity, is used to excite the medium under study. Once the light is absorbed by endogenous or exogenous substances, the target is heated, which in turn generates acoustic waves. This created photoacoustic signal is directly proportional to the light absorption and excitation fluence, (fluences of $\sim \mathrm{mJ} / \mathrm{cm}^{2}$, below tissue damage threshold, are used, and no damage was verified to the tissue), and is not affected by light scattering, since the acoustic scattering signal of tissues is approximately three orders of magnitude less than optical scattering. That fact leads to one of the main advantages of PAI in relation to all-optical imaging methods, which is its ability for deeper imaging (several cms) while a spatial resolution of $\sim 100 \mu \mathrm{m}$ is kept [67]. 


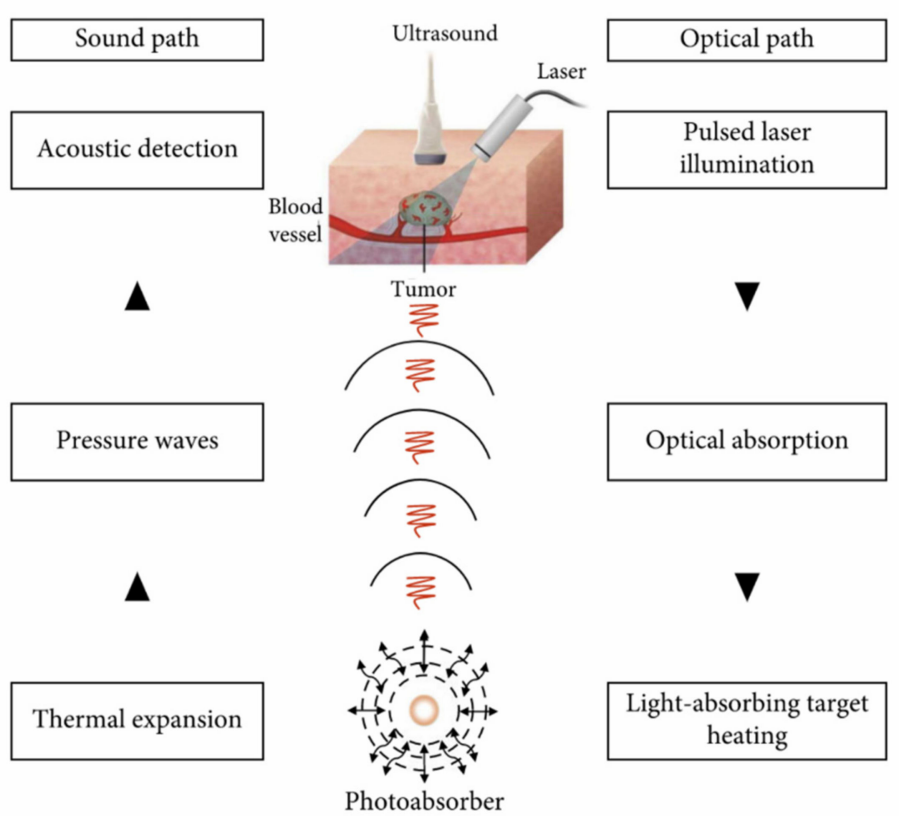

Figure 8. Physical principles of PAI. Figure reprinted with permission from [69].

PAI has emerged in different modalities, as shown in Table 2, from ref. [70]. The different methods for PAI can be implemented with proper modifications from the basic experimental setup. As seen in Table 2, clinical applications of PAI are already being employed. PAI has already been demonstrated for imaging at a molecular or cellular level, as seen in Figure 9, which shows its multiscale capability, particularly photoacoustic computed tomography (PACT), which can be exploited from a single cell or organelles to whole-body small animal dimensions.

Table 2. Different modalities of PAI. Table reprinted with permission from [70].

\begin{tabular}{|c|c|c|c|}
\hline Modality & Application & Advantage & Status \\
\hline PACT & $\begin{array}{l}\text { Peripheral joints, brain, } \\
\text { whole-body study }\end{array}$ & $\begin{array}{l}\text { Real-time and } \\
\text { tomographic imaging }\end{array}$ & $\begin{array}{l}\text { Preclinical and } \\
\text { clinical }\end{array}$ \\
\hline PAM & $\begin{array}{l}\text { Molecular or cellular } \\
\text { imaging }\end{array}$ & $\begin{array}{l}\text { Microcirculation } \\
\text { imaging without } \\
\text { exogenous contrast }\end{array}$ & Preclinical \\
\hline PAE & $\begin{array}{c}\text { Gastrointestinal or } \\
\text { cardiovascular imaging }\end{array}$ & $\begin{array}{c}\text { Gastrointestinal tract } \\
\text { imaging }\end{array}$ & Partially clinical \\
\hline PAFC & $\begin{array}{l}\text { Circulating tumor cells } \\
\text { detection }\end{array}$ & $\begin{array}{l}\text { Quantitative flow } \\
\text { cytometry imaging }\end{array}$ & Preclinical \\
\hline mmPAI & $\begin{array}{l}\text { Circulating tumor cells } \\
\text { detection }\end{array}$ & $\begin{array}{c}\text { Specific contrast } \\
\text { enhancement } \\
\text { availability }\end{array}$ & Preclinical \\
\hline
\end{tabular}

Abbreviations: PAI, photoacoustic imaging; PACT, photoacoustic computed tomography; PAM, photoacoustic microscopy; PAE, photoacoustic endoscopy; PAFC, photoacoustic flow cytometry; mmPAI, magnetomotive PAI.

Whereas endogenous substances are widely used for light absorption, exogenous contrast agents for PAI also play an important role in the image generation from a targeted biological site. Although PAI already provides deeper penetration depth in tissue, wavelengths in NIR-II and the NIR-III biological window will gain further benefits. 

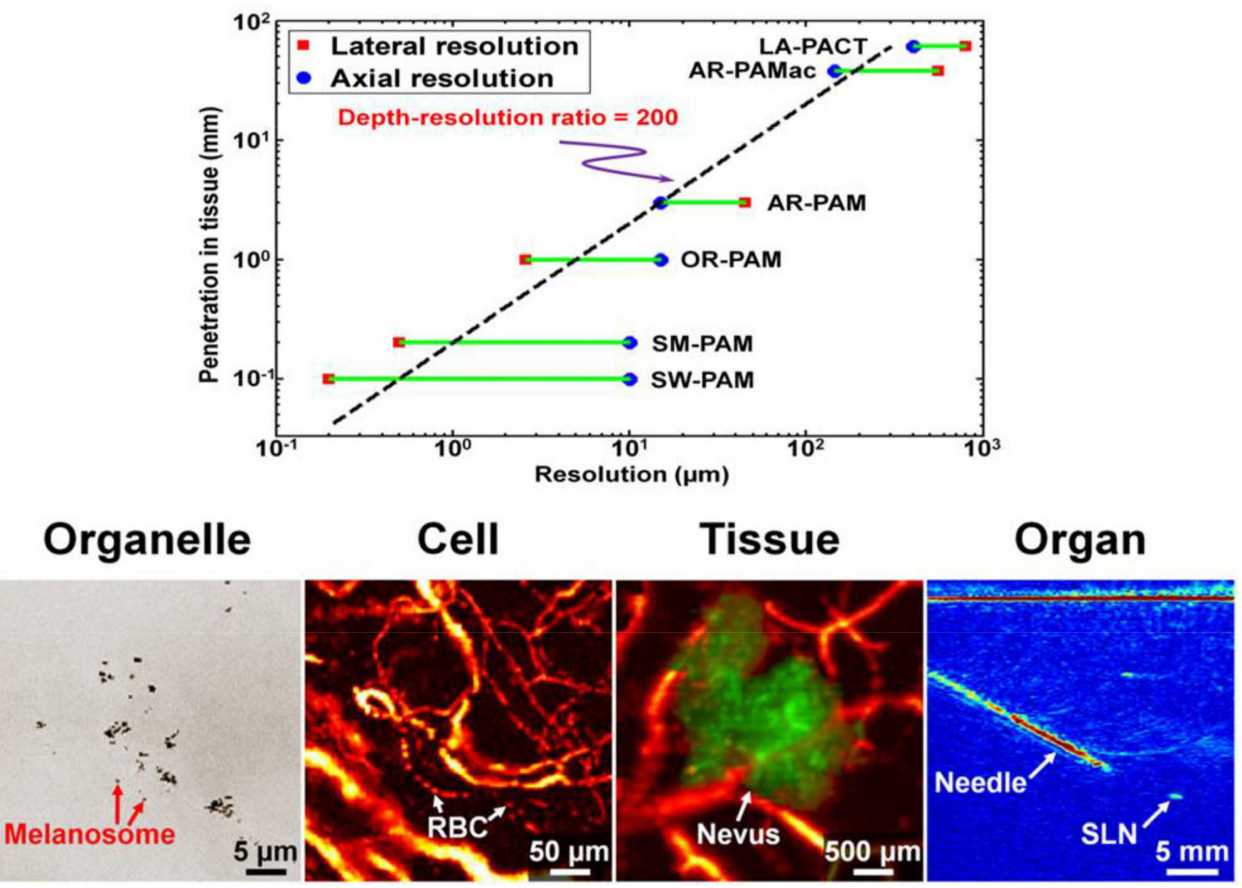

Figure 9. The multiscale capability of PAI. Figure reprinted with permission from [71].

The scope of PAI can be significantly expanded, for instance, to several $\mathrm{cms}$ if deeper tissue-penetrating light in the NIR-II window could be used to excite an exogenous PA contrast agent. In this sense, a recent development is nonlinear PAI using multiphoton absorption (two or more photons) of a NIR light which can be used as a mechanism to overcome or mitigate this challenge [72]. In ref. [73], the photoacoustic Z-scan was employed to estimate the efficiency of photothermal relaxation, therefore characterizing the metrics for a photoacoustic contrast agent to be used for nonlinear photoacoustic imaging. Besides employing endogenous substances or biocompatible exogenous as contrast agents for PAI, nanoparticles as gold-silica nanoshells [74] or conjugated polymer [75] nanoparticles have also been used as a contrast agent for photoacoustic tomography. The applications of PAI in dentistry started in 2006 [76] and have since been used in studies of caries diagnostics, periodontology, dental implants and blood detection in dental pulp [77-82]. Due to the already described difficulties for imaging approaches to detect occlusal caries, besides OCT with the aid of OCA described before, we employed PAI, and more specifically PAM, to image occlusal caries [83]. The results of ref. [83] are shown in Figure 10. Part A shows the experimental setup, which employed a Q-switched Nd:YAG laser with selective wavelengths of $532 \mathrm{~nm}$ and $1064 \mathrm{~nm}$, a pulse width of $6 \mathrm{~ns}$, and a repetition rate of $10 \mathrm{~Hz}$. The laser beam diameter was measured to be approximately $7 \mathrm{~mm}$. The sample (extracted human tooth) was placed on a holder inside a distilled water tank. The entire assembly was supported on a computer-controlled motorized $\mathrm{X}-\mathrm{Y}$ translation stage. The PA signals were acquired by employing an immersion-type ultrasonic transducer V310-N-SU (Olympus, Waltham, MA, USA) with a center frequency of $5 \mathrm{MHz}$. Part B of the figure shows the PA imaging results for excitation at $532 \mathrm{~nm}$ and $1064 \mathrm{~nm}$ for a sound tooth, as well as teeth with incipient and advanced caries. The transducer was partially immersed into the water pointing at the laser beam-tooth interface at $45^{\circ}$ for optimal acoustic coupling with the sample. For the depth measurements shown in part $C$, the PA detector was placed on the tooth side and moved vertically from top to bottom with a computer-controlled Y-axis translation stage. For the measurements, the light fluence was kept at $17 \mathrm{~mJ} / \mathrm{cm}^{2}$, and therefore below the ANSI established threshold. Besides clearly seeing occlusal caries, it is worth noting that, at either wavelength, images with a penetration depth of $4 \mathrm{~mm}$ could be detected-well above the noise floor shown in part C of Figure 10. Further development 
of the setup to perform PAT shall provide further insight into the tooth structure, thus enabling diagnostics of other features.

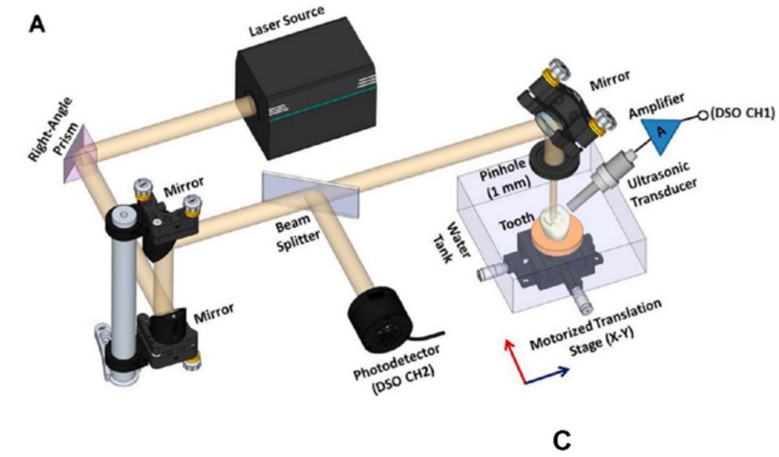

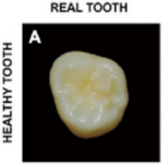
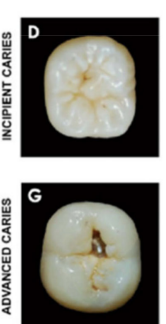

PAI AT $532 \mathrm{~nm}$ PA/As
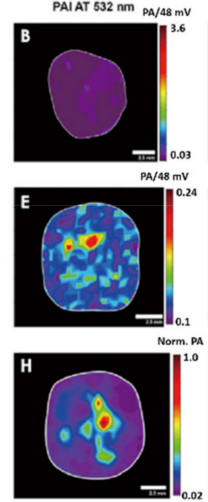
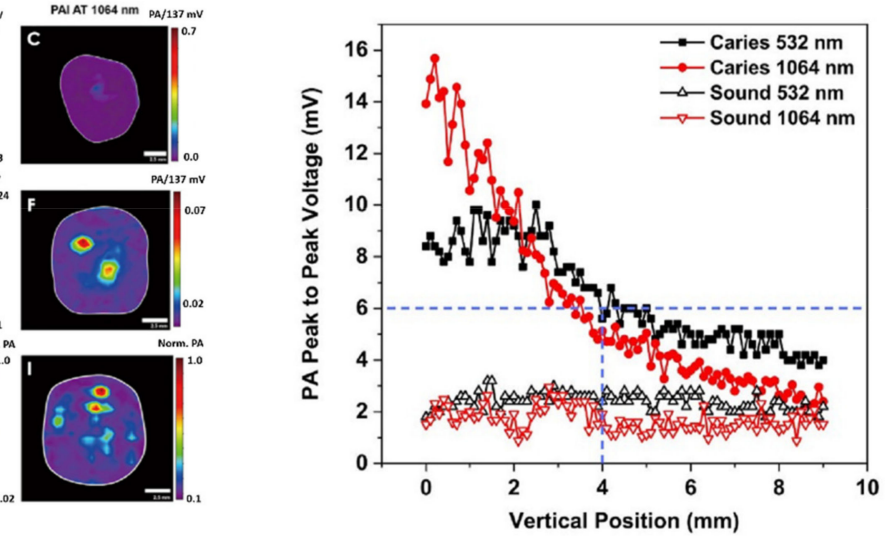

Figure 10. (A) Schematic diagram of the lab-made photoacoustic imaging system. (B) Photoacoustic (PA) images of sound and carious teeth at $532 \mathrm{~nm}$ and $1064 \mathrm{~nm}$ with a $5 \mathrm{MHz}$ photoacoustic detector. The rows represent the sound tooth (A-C); incipient caries (D-F); and advanced caries (G-I) groups. From the left to the right, the first column shows the photographic image of the representative samples, and the second and third columns show the corresponding PA images at $532 \mathrm{~nm}$ and $1064 \mathrm{~nm}$, respectively. PAI: photoacoustic imaging. (C) Peak to peak voltage for the depth of the photoacoustic signal in a tooth with incipient caries. The scale bar is $2.5 \mathrm{~mm}$ long. From ref. [83] with permission.

PAI exploits different types of nanomaterials, and in ref. [70] the readers can find a very good account of PAI being applied to nanomedicine. Among the photoacoustic agents based on nanoparticles, we point out a somewhat unexploited metallic nanoparticle, Titanium Nitride (TiN), which is a promising nanomaterial for biomedical applications, including PAI [84]. TiN is an alternative plasmonic material to other noble metals, such as gold or silver, presenting a redshifted plasmonic extinction band (600-800 nm), well within the first biological window. As we already highlighted, one possible way to improve further depth penetration of light in biotissues is to use wavelengths in the NIR, and benefit from multiphoton absorption. We have recently characterized the nonlinear photoacoustic response of TiN NP using a photoacoustic Z-scan [85]. The TiN NPs in solution was synthesized by femtosecond laser ablation, starting from a solid target, as detailed in ref. [84]. Figures 11 and 12 show the details of the experimental setup, morphological characterization and nonlinear absorption measurements for TiN NP. 
(a)

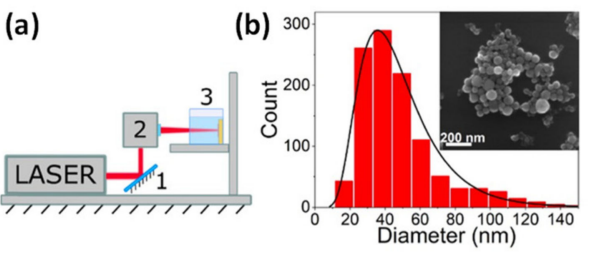

(c)

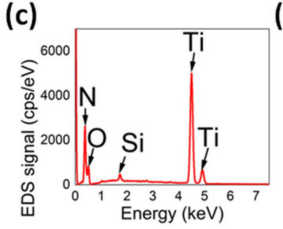

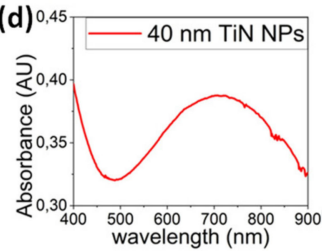

(e)

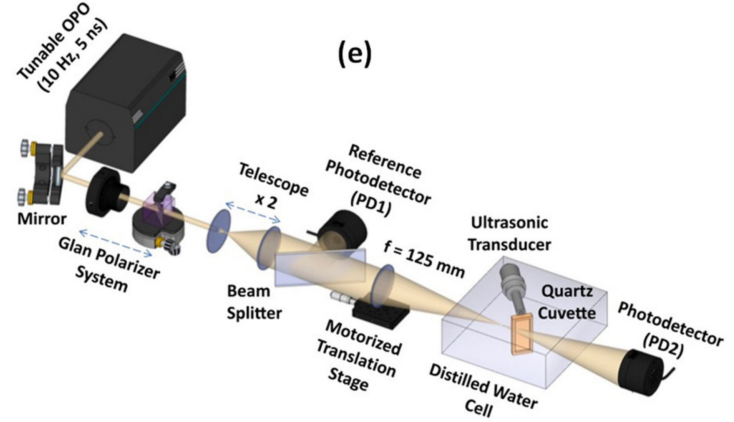

Figure 11. (a) Schematic of the fs laser ablation method; (b) Size distribution of TiN NP prepared by laser ablation; (c) EDS of the NP, identifying the NP contents; (d) Absorbance spectra of $40 \mathrm{~nm}$ TiN NP in acetone; (e) Experimental scheme for photoacoustic Z-scan. Reprinted with permission from ref. [85]. Copyright Optica Publishing Group, 2020.
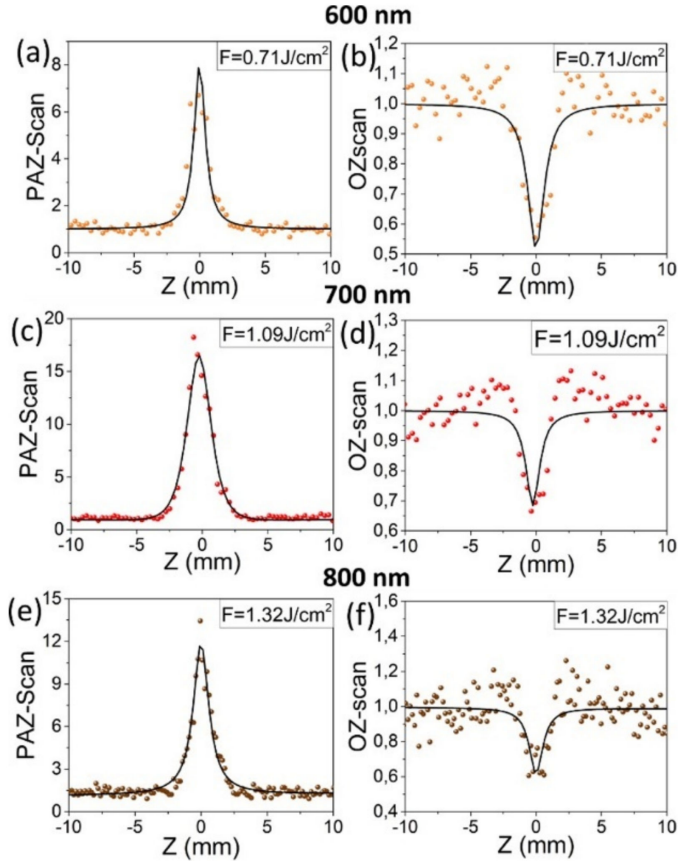

Figure 12. Experimental results (dots) and theoretical fits (lines) of the nonlinear absorption from TiN NP with the OPAZ setup. Left column (a-c), PAZ-scan measurements; right column (d-f), optical Z-scan with open aperture, simultaneously measured. Reprinted with permission from ref. [85]. Copyright Optica Publishing Group, 2020.

As the results from the measurements and theoretical fits (see ref. [85]), the values of nonlinear absorption coefficients from PAZ-scan (and optical Z-scan, between parenthesis) are obtained to be $3.27 \pm 0.17 \times 10^{-8}\left(2.40 \times 10^{-8}\right), 6.41 \pm 0.32 \times 10^{-8}\left(1.04 \times 10^{-8}\right)$, and $3.22 \pm 0.16 \times 10^{-8}\left(1.23 \times 10^{-8}\right) \mathrm{cm} / \mathrm{W}$ for an excitation wavelength of $600 \mathrm{~nm}, 700 \mathrm{~nm}$, and $800 \mathrm{~nm}$, respectively. 
The studies of ref. [85] corroborated the importance of TiN NP for applications where linear and nonlinear absorption plays an important role. Although NP has been used as agents for PAI in a diversity of applications, to the best of our knowledge, applications in nanodentistry have not been reported. TiN may be an important NP for this application, and we present for the first time bidimensional PAM in TiN NP solution in acetone, placed inside an Eppendorf tube. The experimental scheme and setup were similar to Figure 10A, and Figures 13 and 14 show the obtained images. In Figure 13, the proof of concept for the PAM is shown.

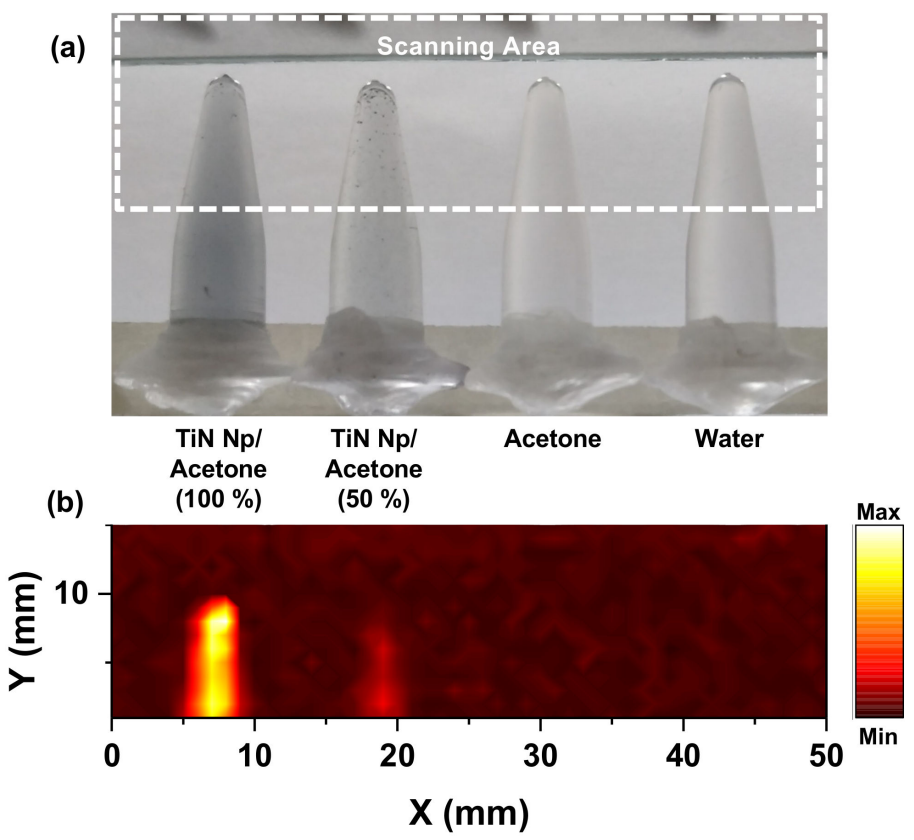

Figure 13. (a) Image of TiN NP/ acetone samples with $100 \%$ and $50 \%$ concentration, acetone and D.I. water, (b) PAI of the samples excited with $6 \mathrm{~mJ} / \mathrm{cm}^{2}, 532 \mathrm{~nm}, 10 \mathrm{~Hz}, \sim 5 \mathrm{~ns}$ pulsed laser source. The PAI is obtained with a single element $5 \mathrm{MHz}$ ultrasonic transducer, (V310-N-SU (Olympus, Waltham, MA, USA)).

The lateral resolution in the PAM system is determined by the diffraction-limited optical spot size [86,87], which is usually limited by the beam size of $1000 \mu \mathrm{m}$. The axial resolution of the PAM $\left(A R_{P A M}\right)$ is related to the velocity of sound in the coupling medium and bandwidth of the ultrasonic transducer as [86,87]:

$$
A R_{P A M}=0.88 \frac{v}{\Delta f_{c}}
$$

where $v$ is the speed of sound in the medium and $\Delta f_{c}$ is the bandwidth of the PA signal which is approximately equal to the ultrasonic transducer bandwidth. Considering, the speed of sound of $1160.96 \mathrm{~m} / \mathrm{s}$ in acetone media (since TiN NPs are suspended in acetone) [88] and a $-6 \mathrm{~dB}$ detection bandwidth of $83.84 \%$, the axial resolution is calculated to be $244 \mu \mathrm{m}$. Such lateral and axial resolution can further be enhanced to subwavelength by employing high numerical aperture objective optics and high bandwidth transducers $[86,89]$. The total time for a full X-Y PAM scan is observed to be around 20-25 min. In Figure 14, we show a very promising result of three-dimensional (3D) PAT imaging of TiN NP in both bare and beneath tissue form. 

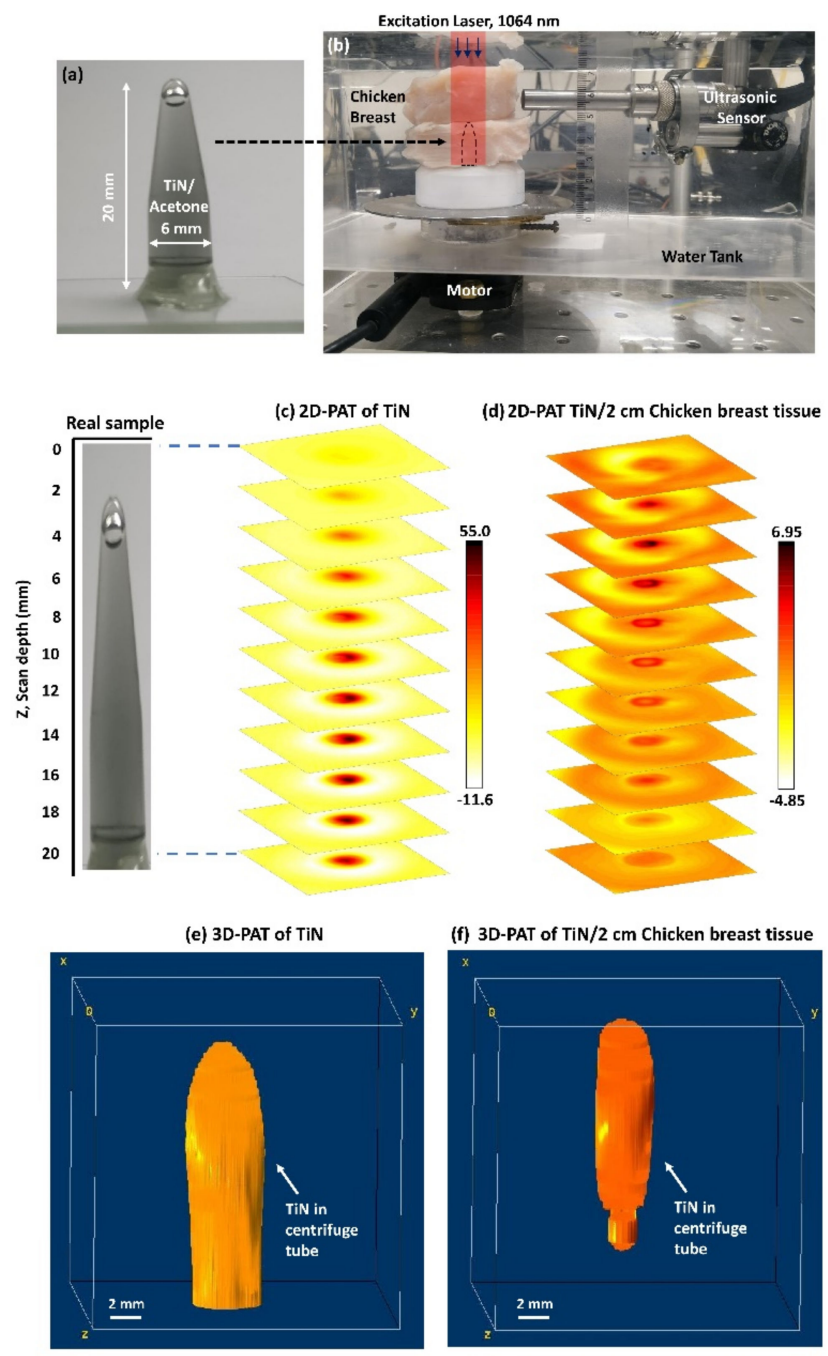

Figure 14. (a) Real picture of TiN/acetone sample filled inside a centrifuge tube (length $=20 \mathrm{~mm}$, $\mathrm{OD}=6 \mathrm{~mm}$ ), (b) 3D-PAT setup containing TiN sample covered with $2 \mathrm{~cm}$ of chicken breast tissue. The PAT is performed for both bare TiN and TiN with chicken under $5 \mathrm{~ns}, 10 \mathrm{~Hz}, 1064 \mathrm{~nm}$ excitation where the peak energy density on the sample surface is maintained to be $40 \mathrm{~mJ} / \mathrm{cm}^{2}$; depth-resolved 2D-PAT reconstructed image slices for (c) TiN and (d) TiN covered with $2 \mathrm{~cm}$ thick chicken breast tissue, obtained from a different scan depth. Every slice dimension is $20 \mathrm{~mm} \times 20 \mathrm{~mm}$; 3D-PAT reconstructed image for (e) TiN and (f) TiN covered with $2 \mathrm{~cm}$ thick chicken breast tissue, obtained after rendering 2D slices (from (c,d)) in Image J software. The axes are scaled to $20 \mathrm{~mm} \times 20 \mathrm{~mm} \times$ $20 \mathrm{~mm}$.

The Eppendorf tube with the TiN NP was placed underneath $2 \mathrm{~cm}$ thick chicken breast tissue, and 2D-PAT imaging was clearly obtained for each vertical position (see Figure 14d). To obtain a 3D-PAT image, the 2D-PAT slices obtained in Figure 14c, d are rendered by Image J software, as shown in Figure 14e,f.

Although we employed only two wavelengths in our demonstration studies-532 nm and $1064 \mathrm{~nm}$ - a tunable source, such as an optical parametric oscillator can be used from the visible to the NIR in PAI systems. If there is enough endogenous absorption in specific wavelengths, or, if exogenous absorbers are to be used, they can be tailored to absorb in required regions. This is one of the material's scientists' important tasks, and nanomaterials are particularly important to be tailored for specific absorption regions. 


\section{Discussion and Conclusions}

Nanodentistry is a young and growing area of research, with an open road ahead, both from the scientific as well as from the technological and clinical viewpoint. This review highlighted several aspects of nanodentistry, with literature examples and some novel results using two different imaging methods, OCT and PAI. With OCT, applications in nanodentistry have already been reported, and several examples were given. Additionally, original results on the use of gold nanostructures-nanoparticles and nanorods-to improve OCT contrast with OCA. The presented results demonstrated the potential of gold nanostructures to improve imaging by $\mathrm{OCT}$, and further studies and applications can be envisaged. We also highlighted and referenced an important method, called nanosensitive OCT, which is a potentially applicable method to nanodentistry. One aspect related to the use of nanomaterials in biotissues, particularly in vivo, is related to nanotoxicity. This is still debatable and there is a vast literature on the subject, as can be seen from ref. [6]. One important point is the concentration of nanoparticles, besides, of course, its material, which should be within a range already accepted and demonstrated not to be harmful [6]. Regarding PAI, two modalities, PAM and PAT, were described, and again these methods are widely known and exploited, even with nanomaterials as exogenous agents. Applications in biotissues, including soft and hard tissue from the oral cavity, have been reported. One important issue to be addressed is the use of PAI with heterogeneous materials. The literature on this subject is still scarce $[90,91]$ and it certainly deserves further studies, particularly when applied to dentistry and nanodentistry. However, PAI applied to nanodentistry, to the best of our knowledge, has yet to be reported. We described a nanomaterial, TiN, which has several advantages for PAI, such as easy fabrication when using femtosecond lasers, biocompatibility and plasmonic enhancement. We have shown its nonlinear optical characterization using a photoacoustic nonlinear method, and also two examples of PAM and PAT images, with a 3D image in the latter case.

Looking ahead, further studies and research in nanodentistry can find important applications in detecting biofilm formation in natural or artificial teeth, which is the starting point for caries or other oral diseases in the case of artificial teeth, particularly in complete or partial dentures. Another way where nanomaterials are important in nanodentistry is in dental materials. This requires new developments, which include rare-earth-doped nanomaterials, which can be simultaneously used for imaging, temperature measurements and curing, using, for instance, photodynamic therapy [92]. Antibacterial nanotherapy is also an interesting field of research. Periodontal diseases can also benefit from nanodentistry, exploiting the so-called nanorobots. An extensive list of different aspects of novel approaches in nanodentistry can be found in ref. [93].

Author Contributions: A.D. and E.J.d.S. contributed to all work related to PAI; G.C.C.R., D.S.L., E.J.d.S., V.S.M.C., C.C.B.d.O.M., M.M.A. and R.B.-S. contributed to the gold nanoparticle OCA and OCT work; D.M.Z. contributed to conceptualization and methodology; M.M.A. contributed to data analysis; D.M.Z. and A.S.L.G. contributed to writing-review; A.D. contributed to editing and review; all the work was supervised by A.S.L.G., who was also responsible for funding acquisition. All authors have read and agreed to the published version of the manuscript.

Funding: This study was carried out under the INCT-INFO (National Institutes of Science and Technology, Institute of Photonics-465.763/2014-6), supported by CNPq/MCTI (Brazilian National Council for Scientific and Technological Development and Ministry of Science, Technology and Innovations) and the PRONEX program (Center of Excellence on Biophotonics and NanophotonicsAPQ-0504-1.05/14); and was sponsored by FACEPE/CNPq (Foundation for Science and Technology of Pernambuco State and Brazilian National Council for Scientific and Technological Development). The authors report no conflict of interest related to this work.

Institutional Review Board Statement: The study was conducted in accordance with the Declaration of Helsinki, and approved by the Ethics Committee on Humans Research of Universidade Federal de Pernambuco (Process number 2.989.712) PAI and (Process number 2.001.287) OCA and OCT. 
Informed Consent Statement: Patient consent was waived, since the present study only used extracted teeth, obtained from the teeth bank of Centro Universitário Tabosa de Almeida (ASCESUNITA), after the Ethics Committee approval.

Data Availability Statement: Data from the authors publications reviewed here are available upon request to the corresponding author.

Acknowledgments: The authors thank the Labfoton team in the Physics Department of UFPE for help in different stages of the research reviewed in this manuscript. We also thank continuous support from CAPES, Brazilian Agency.

Conflicts of Interest: The authors declare no conflict of interest.

\section{References}

1. Yadav, S.K.; Khan, Z.A.; Mishra, B. Impact of Nanotechnology on Socio-Economic Aspects: An Overview. Rev. Nanosci. Nanotechnol. 2013, 2, 127-142. [CrossRef]

2. Miraz, M.H.; Ali, M.; Excell, P.S.; Picking, R. A Review on Internet of Things (IoT), Internet of Everything (IoE) and Internet of Nano Things (IoNT). In Proceedings of the 2015 Internet Technologies and Applications (ITA), Wrexham, UK, 8-11 September 2015; pp. 219-224.

3. Salamanca-Buentello, F.; Daar, A.S. Nanotechnology, Equity and Global Health. Nat. Nanotechnol. 2021, 16, 358-361. [CrossRef]

4. Desai, K.; Somasundaram, J. Nanodentistry-An Overview. Eur. J. Mol. Clin. Med. 2020, 7, $2879-2887$.

5. Foong, L.K.; Foroughi, M.M.; Mirhosseini, A.F.; Safaei, M.; Jahani, S.; Mostafavi, M.; Ebrahimpoor, N.; Sharifi, M.; Varma, R.S.; Khatami, M. Applications of Nano-Materials in Diverse Dentistry Regimes. RSC Adv. 2020, 10, 15430-15460. [CrossRef]

6. Padovani, G.C.; Feitosa, V.P.; Sauro, S.; Tay, F.R.; Durán, G.; Paula, A.J.; Durán, N. Advances in Dental Materials through Nanotechnology: Facts, Perspectives and Toxicological Aspects. Trends Biotechnol. 2015, 33, 621-636. [CrossRef]

7. Melo, M.A.S.; Guedes, S.F.F.; Xu, H.H.K.; Rodrigues, L.K.A. Nanotechnology-Based Restorative Materials for Dental Caries Management. Trends Biotechnol. 2013, 31, 459-467. [CrossRef]

8. Khurshid, Z.; Zafar, M.; Qasim, S.; Shahab, S.; Naseem, M.; Abu Reqaiba, A. Advances in Nanotechnology for Restorative Dentistry. Materials 2015, 8, 717-731. [CrossRef]

9. Yamagata, S.; Hamba, Y.; Nakanishi, K.; Abe, S.; Akasaka, T.; Ushijima, N.; Uo, M.; Iida, J.; Watari, F. Introduction of Rare-EarthElement-Containing ZnO Nanoparticles into Orthodontic Adhesives. Nano Biomed. 2012, 4, 11-17.

10. Yin, I.X.; Zhang, J.; Zhao, I.S.; Mei, M.L.; Li, Q.; Chu, C.H. The Antibacterial Mechanism of Silver Nanoparticles and Its Application in Dentistry. Int. J. Nanomed. 2020, 15, 2555-2562. [CrossRef]

11. Grumezescu, A. Nanobiomaterials in Dentistry: Applications of Nanobiomaterials; William Andrew: Norwich, NY, USA, 2016.

12. Smith, B.R.; Gambhir, S.S. Nanomaterials for In Vivo Imaging. Chem. Rev. 2017, 117, 901-986. [CrossRef]

13. Hannig, M.; Hannig, C. Nanomaterials in Preventive Dentistry. Nat. Nanotechnol. 2010, 5, 565-569. [PubMed]

14. Ellis, P.J. Nanodentistry: The Benefits of Nanotechnology in Dentistry and Its Impact on Oral Health. J. Student Sci. Technol. 2017, 10, 45-50. [CrossRef]

15. Sinha, N.; Kulshreshtha, N.M.; Dixit, M.; Jadhav, I.; Shrivastava, D.; Bisen, P.S. Nanodentistry: Novel Approaches. In Nanostructures for Oral Medicine; Elsevier: Amsterdam, The Netherlands, 2017; pp. 751-776.

16. Adeola, H.A.; Sabiu, S.; Adekiya, T.A.; Aruleba, R.T.; Aruwa, C.E.; Oyinloye, B.E. Prospects of Nanodentistry for the Diagnosis and Treatment of Maxillofacial Pathologies and Cancers. Heliyon 2020, 6, e04890. [CrossRef] [PubMed]

17. Raura, N.; Garg, A.; Arora, A.; Roma, M. Nanoparticle Technology and Its Implications in Endodontics: A Review. Biomater. Res. 2020, 24, 21. [CrossRef]

18. Seth, N.I.; Khan, K.H. Dentistry at the Nano Level: The Advent of Nanodentistry. Int. Healthc. Res. J. 2017, 1, 3-9. [CrossRef]

19. Brun, A.; Moignot, N.; Colombier, M.-L.; Dursun, E. Emerging Nanotechnology in Non-Surgical Periodontal Therapy in Animal Models: A Systematic Review. Nanomaterials 2020, 10, 1414. [CrossRef]

20. Aggarwal, R.; Sounderajah, V.; Martin, G.; Ting, D.S.W.; Karthikesalingam, A.; King, D.; Ashrafian, H.; Darzi, A. Diagnostic Accuracy of Deep Learning in Medical Imaging: A Systematic Review and Meta-Analysis. NPJ Digit. Med. 2021, 4, 65. [CrossRef]

21. Nayak, S.; Patgiri, R. 6G Communication Technology: A Vision on Intelligent Healthcare. In Health Informatics: A Computational Perspective in Healthcare; Springer: Berlin/Heidelberg, Germany, 2021; pp. 1-18.

22. Swanson, E.A.; Fujimoto, J.G. The Ecosystem That Powered the Translation of OCT from Fundamental Research to Clinical and Commercial Impact [Invited]. Biomed. Opt. Express 2017, 8, 1638. [CrossRef]

23. Wang, L.V.; Yao, J. A Practical Guide to Photoacoustic Tomography in the Life Sciences. Nat. Methods 2016, 13, 627-638.

24. Zhu, J.; He, X.; Chen, Z. Perspective: Current Challenges and Solutions of Doppler Optical Coherence Tomography and Angiography for Neuroimaging. APL Photonics 2018, 3, 120902. [CrossRef]

25. Huang, D.; Swanson, E.A.; Lin, C.P.; Schuman, J.S.; Stinson, W.G.; Chang, W.; Hee, M.R.; Flotte, T.; Gregory, K.; Puliafito, C.A.; et al. Optical Coherence Tomography. Science 1991, 254, 1178-1181. [CrossRef] [PubMed]

26. Fujimoto, J.G.; Drexler, W. Introduction to OCT. In Optical Coherence Tomography; Springer International Publishing: Cham, Germany, 2015; pp. 3-64. 
27. Hemmer, E.; Benayas, A.; Légaré, F.; Vetrone, F. Exploiting the Biological Windows: Current Perspectives on Fluorescent Bioprobes Emitting above $1000 \mathrm{Nm}$. Nanoscale Horiz. 2016, 1, 168-184. [CrossRef] [PubMed]

28. Sahyoun, C.C.; Subhash, H.M.; Peru, D.; Ellwood, R.P.; Pierce, M.C. An Experimental Review of Optical Coherence Tomography Systems for Noninvasive Assessment of Hard Dental Tissues. Caries Res. 2020, 54, 43-54. [CrossRef] [PubMed]

29. Shimada, Y.; Sadr, A.; Sumi, Y.; Tagami, J. Application of Optical Coherence Tomography (OCT) for Diagnosis of Caries, Cracks, and Defects of Restorations. Curr. Oral Heal. Rep. 2015, 2, 73-80. [CrossRef]

30. Machoy, M.; Seeliger, J.; Szyszka-Sommerfeld, L.; Koprowski, R.; Gedrange, T.; Woźniak, K. The Use of Optical Coherence Tomography in Dental Diagnostics: A State-of-the-Art Review. J. Healthc. Eng. 2017, 2017, 1-31. [CrossRef]

31. Graça, N.D.; Silva, A.R.; Fernandes, L.O.; da Silva Pedrosa, M.; Guimarães, R.P.; Dos Santos, S.C.; Gomes, A.S.; da Silva, C.H. In Vivo Optical Coherence Tomographic Imaging to Monitor Gingival Recovery and the Adhesive Interface in Aesthetic Oral Rehabilitation: A Case Report. Imaging Sci. Dent. 2019, 49, 171. [CrossRef]

32. Fernandes, L.O.; Mota, C.C.; Oliveira, H.O.; Neves, J.K.; Santiago, L.M.; Gomes, A.S. Optical Coherence Tomography Follow-up of Patients Treated from Periodontal Disease. J. Biophotonics 2019, 12, e201800209. [CrossRef]

33. de Melo, L.S.A.; de Araujo, R.E.; Freitas, A.Z.; Zezell, D.; Vieira, N.D.; Girkin, J.; Hall, A.; Carvalho, M.T.; Gomes, A.S.L. Evaluation of Enamel Dental Restoration Interface by Optical Coherence Tomography. J. Biomed. Opt. 2005, 10, 064027. [CrossRef]

34. Suassuna, F.C.M.; Maia, A.M.A.; Melo, D.P.; Antonino, A.C.D.; Gomes, A.S.L.; Bento, P.M. Comparison of Microtomography and Optical Coherence Tomography on Apical Endodontic Filling Analysis. Dentomaxillofac. Radiol. 2018, 47, 20170174. [CrossRef]

35. de Oliveira, B.P.; Câmara, A.C.; Duarte, D.A.; Gomes, A.S.L.; Heck, R.J.; Antonino, A.C.D.; Aguiar, C.M. Detection of Apical Root Cracks Using Spectral Domain and Swept-Source Optical Coherence Tomography. J. Endod. 2017, 43, 1148-1151. [CrossRef]

36. Fernandes, L.O.; Mota, C.C.B.O.; de Melo, L.S.A.; da Costa Soares, M.U.S.; da Silva Feitosa, D.; Gomes, A.S.L. In Vivo Assessment of Periodontal Structures and Measurement of Gingival Sulcus with Optical Coherence Tomography: A Pilot Study. J. Biophotonics 2017, 10, 862-869. [CrossRef] [PubMed]

37. de Melo Monteiro, G.Q.; Montes, M.A.J.R.; Rolim, T.V.; de Oliveira Mota, C.C.B.; Kyotoku, B.D.B.C.; Gomes, A.S.L.; de Freitas, A.Z. Alternative Methods for Determining Shrinkage in Restorative Resin Composites. Dent. Mater. 2011, 27, e176-e185. [CrossRef] [PubMed]

38. Maia, A.M.A.; Karlsson, L.; Margulis, W.; Gomes, A.S.L. Evaluation of Two Imaging Techniques: Near-Infrared Transillumination and Dental Radiographs for the Detection of Early Approximal Enamel Caries. Dentomaxillofac. Radiol. 2011, 40, 429-433. [CrossRef] [PubMed]

39. Maia, A.M.A.; Fonsêca, D.D.D.; Kyotoku, B.B.C.; Gomes, A.S.L. Characterization of Enamel in Primary Teeth by Optical Coherence Tomography for Assessment of Dental Caries. Int. J. Paediatr. Dent. 2010, 20, 158-164. [CrossRef]

40. Braz, A.K.; Kyotoku, B.B.; Braz, R.; Gomes, A.S. Evaluation of Crack Propagation in Dental Composites by Optical Coherence Tomography. Dent. Mater. 2009, 25, 74-79. [CrossRef]

41. Fonsêca, D.D.D.; Kyotoku, B.B.C.; Maia, A.M.A.; Gomes, A.S.L. In Vitro Imaging of Remaining Dentin and Pulp Chamber by Optical Coherence Tomography: Comparison between 850 and 1280 Nm. J. Biomed. Opt. 2009, 14, 024009. [CrossRef]

42. Alexandrov, S.; Subhash, H.; Leahy, M. Nanosensitive Optical Coherence Tomography for the Study of Changes in Static and Dynamic Structures. Quantum Electron. 2014, 44, 657-663. [CrossRef]

43. Alexandrov, S.A.; Subhash, H.M.; Zam, A.; Leahy, M. Nano-Sensitive Optical Coherence Tomography. Nanoscale 2014, 6, 3545-3549. [CrossRef]

44. Lal, C.; Alexandrov, S.; Rani, S.; Zhou, Y.; Ritter, T.; Leahy, M. Nanosensitive Optical Coherence Tomography to Assess Wound Healing within the Cornea. Biomed. Opt. Express 2020, 11, 3407. [CrossRef]

45. Yi, J.; Radosevich, A.J.; Rogers, J.D.; Norris, S.C.P.; Çapoğlu, İ.R.; Taflove, A.; Backman, V. Can OCT Be Sensitive to Nanoscale Structural Alterations in Biological Tissue? Opt. Express 2013, 21, 9043-9059. [CrossRef]

46. Braz, A.; de Araujo, R.; Ohulchanskyy, T.; Shukla, S.; Bergey, E.; Gomes, A.; Prasad, P. In Situ Gold Nanoparticles Formation: Contrast Agent for Dental Optical Coherence Tomography. J. Biomed. Opt. 2012, 17, 066003. [CrossRef] [PubMed]

47. Carneiro, V.S.M.; Mota, C.C.B.O.; Souza, A.F.; Silva, E.J.; Silva, A.F.; Gerbi, M.E.M.M.; Gomes, A.S.L. Silver Nanoparticles as Optical Clearing Agent Enhancers to Improve Caries Diagnostic by Optical Coherence Tomography. In Proceedings of the Colloidal Nanoparticles for Biomedical Applications XIII, San Francisco, CA, USA, 23 February 2018; Liang, X.-J., Parak, W.J., Osiński, M., Eds.; SPIE: Bellingham, WA, USA, 2018; p. 44.

48. Noronha, V.T.; Paula, A.J.; Durán, G.; Galembeck, A.; Cogo-Müller, K.; Franz-Montan, M.; Durán, N. Silver Nanoparticles in Dentistry. Dent. Mater. 2017, 33, 1110-1126. [CrossRef] [PubMed]

49. Corrêa, J.M.; Mori, M.; Sanches, H.L.; Cruz, A.D.; Poiate, E.; Poiate, I.A. Silver Nanoparticles in Dental Biomaterials. Int. J. Biomater. 2015, 2015, 485275. [CrossRef] [PubMed]

50. Teixeira, J.A.; e Silva, A.V.C.; dos Santos Júnior, V.E.; de Melo Júnior, P.C.; Arnaud, M.; Lima, M.G.; Flores, M.A.P.; Stamford, T.C.M.; Dias Pereira, J.R.; Ribeiro Targino, A.G.; et al. Effects of a New Nano-Silver Fluoride-Containing Dentifrice on Demineralization of Enamel and Streptococcus Mutans Adhesion and Acidogenicity. Int. J. Dent. 2018, 2018, 1-9. [CrossRef]

51. Tuchin, V.V.; Maksimova, I.L.; Zimnyakov, D.A.; Kon, I.L.; Mavlyutov, A.H.; Mishin, A.A. Light Propagation in Tissues with Controlled Optical Properties. J. Biomed. Opt. 1997, 2, 401. [CrossRef]

52. Costantini, I.; Cicchi, R.; Silvestri, L.; Vanzi, F.; Pavone, F.S. In-Vivo and Ex-Vivo Optical Clearing Methods for Biological Tissues: Review. Biomed. Opt. Express 2019, 10, 5251. [CrossRef] 
53. Tuchin, V.V.; Zhu, D.; Genina, E.A. Handbook of Tissue Optical Clearing: New Prospects in Optical Imaging; CRC Press: Boca Raton, FL, USA, 2022.

54. Wen, X.; Jacques, S.L.; Tuchin, V.V.; Zhu, D. Enhanced Optical Clearing of Skin in Vivo and Optical Coherence Tomography In-Depth Imaging. J. Biomed. Opt. 2012, 17, 066022. [CrossRef]

55. Larin, K.V.; Ghosn, M.G.; Bashkatov, A.N.; Genina, E.A.; Trunina, N.A.; Tuchin, V.V. Optical Clearing for OCT Image Enhancement and In-Depth Monitoring of Molecular Diffusion. IEEE J. Sel. Top. Quantum Electron. 2012, 18, 1244-1259. [CrossRef]

56. Sudheendran, N.; Mohamed, M.; Ghosn, M.G.; Tuchin, V.V.; Larin, K.V. Assessment of Tissue Optical Clearing as a Function of Glucose Concentration Using Optical Coherence Tomography. J. Innov. Opt. Health Sci. 2010, 3, 169-176. [CrossRef]

57. Bykov, A.; Hautala, T.; Kinnunen, M.; Popov, A.; Karhula, S.; Saarakkala, S.; Nieminen, M.T.; Tuchin, V.; Meglinski, I. Imaging of Subchondral Bone by Optical Coherence Tomography upon Optical Clearing of Articular Cartilage. J. Biophotonics 2016, 9 , 270-275. [CrossRef]

58. Hu, J.; Romero Abujetas, D.; Tsoutsi, D.; Leggio, L.; Rivero, F.; Martín Rodríguez, E.; Aguilar Torres, R.; Sánchez-Gil, J.A.; Loro Ramírez, H.; Gallego, D.; et al. Invited Article: Experimental Evaluation of Gold Nanoparticles as Infrared Scatterers for Advanced Cardiovascular Optical Imaging. APL Photonics 2018, 3, 080803. [CrossRef]

59. Si, P.; Yuan, E.; Liba, O.; Winetraub, Y.; Yousefi, S.; SoRelle, E.D.; Yecies, D.W.; Dutta, R.; de la Zerda, A. Gold Nanoprisms as Optical Coherence Tomography Contrast Agents in the Second Near-Infrared Window for Enhanced Angiography in Live Animals. ACS Nano 2018, 12, 11986-11994. [CrossRef] [PubMed]

60. Oldenburg, A.L.; Hansen, M.N.; Ralston, T.S.; Wei, A.; Boppart, S.A. Imaging Gold Nanorods in Excised Human Breast Carcinoma by Spectroscopic Optical Coherence Tomography. J. Mater. Chem. 2009, 19, 6407. [CrossRef] [PubMed]

61. Zagaynova, E.V.; Shirmanova, M.V.; Kirillin, M.Y.; Khlebtsov, B.N.; Orlova, A.G.; Balalaeva, I.V.; Sirotkina, M.A.; Bugrova, M.L.; Agrba, P.D.; Kamensky, V.A. Contrasting Properties of Gold Nanoparticles for Optical Coherence Tomography: Phantom, in Vivo Studies and Monte Carlo Simulation. Phys. Med. Biol. 2008, 53, 4995-5009. [CrossRef]

62. Maia, A.M.A.; de Freitas, A.Z.; de Campello, S.; Gomes, A.S.L.; Karlsson, L. Evaluation of Dental Enamel Caries Assessment Using Quantitative Light Induced Fluorescence and Optical Coherence Tomography. J. Biophotonics 2016, 9, 596-602. [CrossRef]

63. Melo, M.; Pascual, A.; Camps, I.; del Campo, Á.; Ata-Ali, J. Caries Diagnosis Using Light Fluorescence Devices in Comparison with Traditional Visual and Tactile Evaluation: A Prospective Study in 152 Patients. Odontology 2017, 105, 283-290. [CrossRef]

64. Brito-Silva, A.M.; Sobral-Filho, R.G.; Barbosa-Silva, R.; de Araújo, C.B.; Galembeck, A.; Brolo, A.G. Improved Synthesis of Gold and Silver Nanoshells. Langmuir 2013, 29, 4366-4372. [CrossRef]

65. Popescu, D.P.; Sowa, M.G.; Hewko, M.D.; Choo-Smith, L.-P. Assessment of Early Demineralization in Teeth Using the Signal Attenuation in Optical Coherence Tomography Images. J. Biomed. Opt. 2008, 13, 054053. [CrossRef]

66. Liang, Y.; Yuan, W.; Mavadia-Shukla, J.; Li, X. Optical Clearing for Luminal Organ Imaging with Ultrahigh-Resolution Optical Coherence Tomography. J. Biomed. Opt. 2016, 21, 081211. [CrossRef]

67. Xu, M.; Wang, L.V. Photoacoustic Imaging in Biomedicine. Rev. Sci. Instrum. 2006, 77, 041101. [CrossRef]

68. Erfanzadeh, M.; Zhu, Q. Photoacoustic Imaging with Low-Cost Sources; A Review. Photoacoustics 2019, 14, 1-11. [CrossRef] [PubMed]

69. Gargiulo, S.; Albanese, S.; Mancini, M. State-of-the-Art Preclinical Photoacoustic Imaging in Oncology: Recent Advances in Cancer Theranostics. Contrast Media Mol. Imaging 2019, 2019, 1-24. [CrossRef] [PubMed]

70. Zou, C.; Wu, B.; Dong, Y.; Song, Z.; Zhao, Y.; Ni, X.; Yang, Y.; Liu, Z. Biomedical Photoacoustics: Fundamentals, Instrumentation and Perspectives on Nanomedicine. Int. J. Nanomed. 2016, 12, 179-195. [CrossRef] [PubMed]

71. Aldrich, M.B.; Marshall, M.V.; Sevick-Muraca, E.M.; Lanza, G.; Kotyk, J.; Culver, J.; Wang, L.V.; Uddin, J.; Crews, B.C.; Marnett, L.J.; et al. Seeing It through: Translational Validation of New Medical Imaging Modalities. Biomed. Opt. Express 2012, 3, 764. [CrossRef] [PubMed]

72. Wang, D.; Wei, W.; Singh, A.; He, G.S.; Kannan, R.; Tan, L.-S.; Chen, G.; Prasad, P.N.; Xia, J. Nonlinear Photoacoustic Imaging by in Situ Multiphoton Upconversion and Energy Transfer. ACS Photonics 2017, 4, 2699-2705. [CrossRef]

73. Maldonado, M.E.; Das, A.; Jawaid, A.M.; Ritter, A.J.; Vaia, R.A.; Nagaoka, D.A.; Vianna, P.G.; Seixas, L.; de Matos, C.J.S.; Baev, A.; et al. Nonlinear Optical Interactions and Relaxation in 2D Layered Transition Metal Dichalcogenides Probed by Optical and Photoacoustic Z-Scan Methods. ACS Photonics 2020, 7, 3440-3447. [CrossRef]

74. Wang, Y.; Xie, X.; Wang, X.; Ku, G.; Gill, K.L.; O’Neal, D.P.; Stoica, G.; Wang, L.V. Photoacoustic Tomography of a Nanoshell Contrast Agent in the in Vivo Rat Brain. Nano Lett. 2004, 4, 1689-1692. [CrossRef]

75. Guo, B.; Sheng, Z.; Kenry, K.; Hu, D.; Lin, X.; Xu, S.; Liu, C.; Zheng, H.; Liu, B. Biocompatible Conjugated Polymer Nanoparticles for Highly Efficient Photoacoustic Imaging of Orthotopic Brain Tumors in the Second Near-Infrared Window. Mater. Horiz. 2017, 4, 1151-1156. [CrossRef]

76. Kim, K.; Witte, R.; Koh, I.; Ashkenazi, S.; O’Donnell, M. Early Detection of Dental Caries Using Photoacoustics; Oraevsky, A.A., Wang, L.V., Eds.; SPIE: Bellingham, WA, USA, 2006; p. 60860G.

77. Cheng, R.; Shao, J.; Gao, X.; Tao, C.; Ge, J.; Liu, X. Noninvasive Assessment of Early Dental Lesion Using a Dual-Contrast Photoacoustic Tomography. Sci. Rep. 2016, 6, 21798. [CrossRef]

78. Koyama, T.; Kakino, S.; Matsuura, Y. A Feasibility Study of Photoacoustic Detection of Hidden Dental Caries Using a Fiber-Based Imaging System. Appl. Sci. 2018, 8, 621. [CrossRef] 
79. Hughes, D.A.; Sampathkumar, A.; Longbottom, C.; Kirk, K.J. Imaging and Detection of Early Stage Dental Caries with an All-Optical Photoacoustic Microscope. In Proceedings of the 13th Anglo-French Physical Acoustics Conference (AFPAC2014), Selsdon Park Hotel, Croydon, UK, 15-17 January 2014; p. 12002.

80. Lin, C.Y.; Chen, F.; Hariri, A.; Chen, C.J.; Wilder-Smith, P.; Takesh, T.; Jokerst, J.V. Photoacoustic Imaging for Noninvasive Periodontal Probing Depth Measurements. J. Dent. Res. 2018, 97, 23-30. [CrossRef] [PubMed]

81. Lee, D.; Kim, C.; Park, S. Dual-Modal Photoacoustic and Ultrasound Imaging of Dental Implants. In Proceedings of the Photons Plus Ultrasound: Imaging and Sensing, San Francisco, CA, USA, 19 February 2018; Oraevsky, A.A., Wang, L.V., Eds.; SPIE: Bellingham, WA, USA, 2018; p. 10.

82. Yamada, A.; Kakino, S.; Matsuura, Y. Detection of Photoacoustic Signals from Blood in Dental Pulp. Opt. Photonics J. 2016, 6, 229-236. [CrossRef]

83. Da Silva, E.J.; de Miranda, E.M.; de Oliveira Mota, C.C.B.; Das, A.; Gomes, A.S.L. Photoacoustic Imaging of Occlusal Incipient Caries in the Visible and Near-Infrared Range. Imaging Sci. Dent. 2021, 51, 107. [CrossRef] [PubMed]

84. Popov, A.A.; Tselikov, G.; Dumas, N.; Berard, C.; Metwally, K.; Jones, N.; Al-Kattan, A.; Larrat, B.; Braguer, D.; Mensah, S.; et al. Laser- Synthesized TiN Nanoparticles as Promising Plasmonic Alternative for Biomedical Applications. Sci. Rep. 2019, 9, 1194. [CrossRef]

85. Maldonado, M.E.; Das, A.; Gomes, A.S.L.; Popov, A.A.; Klimentov, S.M.; Kabashin, A.V. Nonlinear Photoacoustic Response of Suspensions of Laser-Synthesized Plasmonic Titanium Nitride Nanoparticles. Opt. Lett. 2020, 45, 6695. [CrossRef]

86. Yao, J.; Wang, L.V. Photoacoustic Microscopy. Laser Photon. Rev. 2013, 7, 758-778. [CrossRef]

87. Jeon, S.; Kim, J.; Lee, D.; Baik, J.W.; Kim, C. Review on Practical Photoacoustic Microscopy. Photoacoustics 2019, 15, 100141. [CrossRef]

88. Touriño, A.; Casás, L.M.; Marino, G.; Iglesias, M.; Orge, B.; Tojo, J. Liquid Phase Behaviour and Thermodynamics of Acetone+methanol+n-Alkane $\left(C_{9}-C_{12}\right)$ Mixtures. Fluid Phase Equilib. 2003, 206, 61-85. [CrossRef]

89. Zhang, C.; Maslov, K.; Wang, L.V. Subwavelength-Resolution Label-Free Photoacoustic Microscopy of Optical Absorption in Vivo. Opt. Lett. 2010, 35, 3195. [CrossRef]

90. Zheng, S.; Yixuan, J. An Image Reconstruction Method for Endoscopic Photoacoustic Tomography in Tissues with Heterogeneous Sound Speed. Comput. Biol. Med. 2019, 110, 15-28. [CrossRef]

91. Schoonover, R.W.; Anastasio, M.A. Image Reconstruction in Photoacoustic Tomography Involving Layered Acoustic Media. J. Opt. Soc. Am. A 2011, 28, 1114. [CrossRef] [PubMed]

92. Yakovliev, A.; Ohulchanskyy, T.Y.; Ziniuk, R.; Dias, T.; Wang, X.; Xu, H.; Chen, G.; Qu, J.; Gomes, A.S.L. Noninvasive Temperature Measurement in Dental Materials Using $\mathrm{Nd}^{3+}, \mathrm{Yb}^{3+}$ Doped Nanoparticles Emitting in the Near Infrared Region. Part. Part. Syst. Charact. 2020, 37, 1900445. [CrossRef]

93. Andronescu, E.; Grumezescu, A.M. Nanostructures in Therapeutic Medicine Series: Nanostructures for Oral Medicine; Elsevier: Amsterdam, The Netherlands, 2017; Chapter 24. 